\title{
Comparative genomics and phylogenetic relationships of two endemic and endangered species (Handeliodendron bodinieri and Eurycorymbus cavaleriei) of two monotypic genera within Sapindales
}

Jiaxin Yang ${ }^{1,2,3,4}$, Guoxiong $\mathrm{Hu}^{4^{*}}$ and Guangwan $\mathrm{Hu}^{1,2^{*}}$

\begin{abstract}
Background: Handeliodendron Rehder and Eurycorymbus Hand.-Mazz. are the monotypic genera in the Sapindaceae family. The phylogenetic relationship of these endangered species Handeliodendron bodinieri (Lévl.) Rehd. and Eurycorymbus cavaleriei (Lévl.) Rehd. et Hand.-Mazz. with other members of Sapindaceae s.l. is not well resolved. A previous study concluded that the genus Aesculus might be paraphyletic because Handeliodendron was nested within it based on small DNA fragments. Thus, their chloroplast genomic information and comparative genomic analysis with other Sapindaceae species are necessary and crucial to understand the circumscription and plastome evolution of this family.

Results: The chloroplast genome sizes of Handeliodendron bodinieri and Eurycorymbus cavaleriei are 151,271 and $158,690 \mathrm{bp}$, respectively. Results showed that a total of 114 unique genes were annotated in H. bodinieri and $E$. cavaleriei, and the ycf1 gene contained abundant SSRs in both genomes. Comparative analysis revealed that gene content, PCGs, and total GC content were remarkably similar or identical within 13 genera from Sapindaceae, and the chloroplast genome size of four genera was generally smaller within the family, including Acer, Dipteronia, Aesculus, and Handeliodendron. IR boundaries of the H. bodinieri showed a significant contraction, whereas it presented a notable expansion in E. cavaleriei cp genome. YCf1, ndhC-trnV-UAC, and rp/32-trnL-UAG-cCSA were remarkably divergent regions in the Sapindaceae species. Analysis of selection pressure showed that there are a few positively selected genes. Phylogenetic analysis based on different datasets, including whole chloroplast genome sequences, coding sequences, large single-copy, small single-copy, and inverted repeat regions, consistently demonstrated that $H$. bodinieri was sister to the clade consisting of Aesculus chinensis and A. wangii and strongly support Eurycorymbus cavaleriei as sister to Dodonaea viscosa.
\end{abstract}

Conclusion: This study revealed that the cp genome size of the Hippocastanoideae was generally smaller compared to the other subfamilies within Sapindaceae, and three highly divergent regions could be used as the specific DNA

\footnotetext{
*Correspondence: gxhu@gzu.edu.cn; guangwanhu@wbgcas.cn

${ }^{2}$ Sino-Africa Joint Research Center, Chinese Academy of Sciences,

Wuhan 430074, China

${ }^{4}$ College of Life Sciences, Guizhou University, Guiyang 550025, Guizhou,

China

Full list of author information is available at the end of the article
}

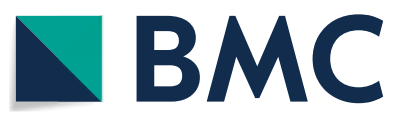

(c) The Author(s) 2022. Open Access This article is licensed under a Creative Commons Attribution 4.0 International License, which permits use, sharing, adaptation, distribution and reproduction in any medium or format, as long as you give appropriate credit to the original author(s) and the source, provide a link to the Creative Commons licence, and indicate if changes were made. The images or other third party material in this article are included in the article's Creative Commons licence, unless indicated otherwise in a credit line to the material. If material is not included in the article's Creative Commons licence and your intended use is not permitted by statutory regulation or exceeds the permitted use, you will need to obtain permission directly from the copyright holder. To view a copy of this licence, visit http://creativecommons.org/licenses/by/4.0/. The Creative Commons Public Domain Dedication waiver (http://creativeco mmons.org/publicdomain/zero/1.0/) applies to the data made available in this article, unless otherwise stated in a credit line to the data. 
barcodes within Sapindaceae. Phylogenetic results strongly support that the subdivision of four subfamilies within Sapindaceae, and Handeliodendron is not nested within the genus Aesculus.

Keywords: Endangered, Monotypic genus, Endemic, Handeliodendron, Eurycorymbus, Chloroplast genome, Phylogenetic analysis, Sapindaceae

\section{Introduction}

Handeliodendron bodinieri (Lévl.) Rehd. and Eurycorymbus cavaleriei (Lévl.) Rehd. et Hand.-Mazz. (Sapindaceae) are deciduous woody plants endemic to China, and belong to the two monotypic genera Handeliodendron and Eurycorymbus, respectively [1]. Previous studies revealed that $H$. bodinieri and E. cavaleriei are economically important plants. Their seed kernel have been used as raw materials for producing biodiesel, sources of protein and edible oil and are of high medicinal and nutritional values $[2,3] . H$. bodinieri species are mainly distributed in the south Guizhou province and the northwest of Guangxi Zhuang Autonomous Region [1], and a small population is found in Yunan province, China [4]. E. cavaleriei are distributed in Fujian, Guangdong, Guangxi, Guizhou, Hunan, Jiangxi, Sichuan, Taiwan, and Yunnan provinces [5]. The two species are categorized as endangered according to Information System of Chinese Rare and Endangered Plants (ISCREP) (http://www. iplant.cn/rep/). Significantly, H. bodinieri has been listed among the level-I state-protected wild plants, whereas E. cavaleriei has been classified as the level-II state-protected wild plants in the list. In addition, E. cavaleriei was designated as Near Threatened (NT) by the International Union for Conservation of Nature (IUCN) Red List (https://www.iucnredlist.org/species/31353/9628640).

Historically, there were considerable controversies about the circumscription of Sapindaceae, predominantly the traditionally defined Aceraceae and Hippocastanaceae should be incorporated into Sapindaceae or separated. The concept of Sapindaceae s. str. Was first proposed by Jussieu in 1789, that supported that the family is different from Aceraceae. After this, the works of Radlkofer maintained the family distinct from Aceraceae and Hippocastanaceae, and proposed the first worldwide system of classification for Sapindaceae [6, 7]. In this classification system of Radlkofer, Sapindaceae was divided into two subfamilies Eusapindaceae and Dyssapindaceae. The Eusapindaceae consists of nine tribes, including Paullinieae, Thouinieae, Sapindeae, Aphanieae, Lepisantheae, Melicocceae, Nephelieae, and Cupanieae, whereas the Dyssapindaceae contains five tribes (including Koelreuterieae, Cossignieae, Doratoxyleae, and Harpullieae). Muller and Leenhouts [8] proposed the revised classification of Sapindaceae based upon the macromorphology and pollen morphology, in which the tribe Aphanieae was incorporated into Lepisantheae. They considered Aceraceae and Hippocastanaceae as related to the Sapindaceae basing on pollen character, thus suggested that they be retained as tribes within the Sapindaceae. However, most classification systems [9-11] maintained Aceraceae and Hippocastanaceae as distinct families. On the basis of phytochemistry, Umadevi and Daniel [12] proposed a system of classification for Sapindaceae. They divided the family into four subfamilies: Aceroideae (including all members of the former Aceraceae), Sapindoideae (including the former Hippocastanaceae as a tribe), Dodoneoideae (Dodonaea), and Koelreuterioideae (all the other tribes of Dodoneoideae of Radlkofer). Judd [13] agreed with the broader concept of Sapindaceae and supported the inclusion of both families within Sapindaceae. The system of Thorne [14] divided the family into five subfamilies: Dodonaeoideae, Koelreuterioideae, Sapindoieae, Hippocastanoideae (Aesculus and Billia), and Aceroideae (Acer and Dipteronia). Based on plastid genes mat $K$ and $r b c L$, Harrington et al. [15] conducted the phylogenetic analysis in Sapindaceae, and supported the recognition of a broadly defined Sapindaceae incorporating Aceraceae and Hippocastanaceae. They further proposed that the subdivision of four subfamilies within Sapindaceae: Xanthoceroideae (including the single genus Xanthoceras), Hippocastanoideae, Dodonaeoideae, and Sapindoideae. The work of Harrington et al. [15] has been adopted by Thorne et al. [16]. By increasing taxon sampling and expanding DNA data, Buerki et al. [17] revealed the relationships at subfamilial and tribal levels in Sapindaceae. They supported the merging of Aceraceae and Hippocastanaceae into Sapindaceae, and recognized four subfamilies within Sapindaceae (Xanthoceroideae, Hippocastanoideae, Dodonaeoideae, and Sapindoideae). Nevertheless, based on molecular sequence data, morphology and biogeography, Buerki et al. [18] resurrected the traditional families Aceraceae and Hippocastanaceae and further proposed a new family, Xanthoceraceae (including the single genus Xanthoceras). The concept of a broadly defined Sapindaceae that includes Aceraceae, Hippocastanaceae, and Xanthoceras, was adopted by the newly published Angiosperm Phylogeny Group (APG) [19].

For the Handeliodendron bodinieri, Rehder [20] proposed the new genus Handeliodendron, and it resembles the Hippocastanaceae in opposite and digitately 
5-foliolate leaves. However, other characters showed that it is a closer affinity with the Sapindaece and is best placed in the tribe Harpullieae [20]. The work of Muller and Leenhouts [8] considered that Delavaya and Handeliodendron are the intermediate between Harpullieae and Hippocastanaceae. Judd [13] supported that Handeliodendron should be classified together with members of the Hippocastanaceae. The molecular phylogenetic analysis of Sapindaceae demonstrated that Handeliodendron should be transferred from Harpullieae to tribe Hippocastaneae (subfamily Hippocastanoideae) containing Aesculus and Billia, and strongly supported H. bodinieri was sister to the Aesculus plus Billia [15]. According to Flora of China, Xia et al. [21] maintained the Hippocastanaceae as a distinct family, comprised of Handeliodendron, Aesculus, and Billia. Buerki et al. [17] supported that Handeliodendron, Aesculus, and Billia were members of the Aesculus group in the subfamily Hippocastanoideae, but their work lacked samples of Handeliodendron and Billia. By increasing samples and DNA markers, Buerki et al. [18] concluded the genus Aesculus might be paraphyletic because the Handeliodendron and Billia were nested within it, but the relationship was only weakly supported (for Handeliodendron: $\mathrm{BS}=68$; for Billia: $\mathrm{BS}=76$ ). For the genus Eurycorymbus, it was a component of the Harpullieae in the subfamily Dodonaeoideae $[6,8]$. Molecular analyses indicated that Eurycorymbus belongs to a member of the Dodoneae group in the Dodonaeoideae, the results strongly supported E. cavaleriei was sister to Euphorianthus longifolius $[17,18]$.

Despite the systematic position of Handeliodendron bodinieri and Eurycorymbus cavaleriei tending to show more stability within the Sapindaceae, previous studies were mainly based on the morphology and/or limited DNA regions. At present, the next-generation sequencing (NGS) technologies and bioinformatics tools bring great convenience for acquiring and analyzing genomescale data, while obtaining genome-scale nuclear data remains significantly difficult in terms of expense. On the contrary, the plastid genome has become extremely easy to obtain because of its highly conserved nature and much smaller size. Meanwhile, an increasing number of the chloroplast genomes have been widely applied to solve phylogenetic relationships at different taxonomical levels within angiosperms [22-29]. Besides, recent studies have demonstrated chloroplast genome can serve as super barcodes for species and taxonomic groups [23, 30-33]. There are some cp genomes in Sapindaceae s.l. species have been reported and deposited in GenBank database, like Acer [34], Dodonaea [35], Aesculus [36-39], Dimocarpus [40], most of which were the genus Acer [41-46]. We also noticed that previous studies have revealed the complete cp genomes of $H$. bodinieri and $E$. cavaleriei [47-49], but focus mainly on the size and gene contents of the cp genome, lacking detailed comparative genomic and comprehensive phylogenetic analysis. Moreover, a comprehensive genomics analysis is still a useful framework for understanding plastome evolution and phylogenetic relationships within Sapindaceae. Getorganelle [50] was used to accurately assemble the $\mathrm{cp}$ genome of $H$. bodinieri and E. cavaleriei, which underpins the further study. Due to insufficient molecular data, the result of Tian, et al. [49] showed $H$. bodinieri is closely related to the genus Mangifera. However, according to the work of Harrington et al. [15], H. bodinieri was closely related to Aesculus plus Billia. Therefore, it is necessary to perform a comprehensive cp genomic comparison and phylogenetic analysis in the Sapindaceae.

In the current study, we sequenced and assembled the complete chloroplast genomes of Handeliodendron bodinieri and Eurycorymbus cavaleriei. The main objectives of this study were to 1) compare and analyze the gene organizations of $H$. bodinieri and $E$. cavaleriei $\mathrm{cp}$ genomes; 2) reveal the $\mathrm{cp}$ genome structural and size variation in Sapindaceae; 3) explore the highly divergent regions of the cp genomes from Sapindaceae species; 4) reconstruct the phylogeny of $H$. bodinieri and $E$. cavaleriei within Sapindales at the cp genome level.

\section{Materials and methods}

\section{Plant material and DNA extraction}

Fresh leaves of cultivated plants Handeliodendron bodinieri (voucher Number: HXZ-Z-0001) and Eurycorymbus cavaleriei (voucher Number: Hu-Z-0001) were collected from Guizhou Botanical Garden and Pingtang county of Guizhou, China, respectively. These sample collections were approved by the Guizhou Academy of Sciences and Guizhou Forestry Bureau, Guizhou province, China. The voucher specimens were deposited in the Herbarium of Nature Museum, Guizhou University (GACP). Total genomic DNA of E. cavaleriei was extracted following a modified cetyltrimethylammonium bromide (CTAB) approach [51], while that of $H$. bodinieri could not be obtained by the same method. Total genomic DNA of $H$. bodinieri was eventually extracted using a CTAB approach as improved by Tong [52] .

\section{Chloroplast genome sequencing, assembly and annotation} The genome was sequenced using the Illumina Hiseq 2500 platform at Wuhan BGI Technology Service Co., Ltd. (Wuhan, China). Complete chloroplast genomes of Handeliodendron bodinieri and Eurycorymbus cavaleriei were assembled from raw reads using GetOrganelle v1.7.1 with default parameters [50], which will automatically call the SPAdes [53], Bowtie2 [54] and BLAST 
[55]. The assembly workflow includes five key steps: 1 ). Mapping reads to seed and assembling seed-mapped reads for parameter estimation; 2). Recruiting more target-associated reads through extending iterations; $3)$. Conducting de novo assembly; 4). Roughly filtering for target-like contigs; 5). Identifying target contigs and exporting all configurations [50]. The final assembly results were checked using Bandage [56].

Complete chloroplast genomes were annotated using the PGA (Plastid Genome Annotator) software [57], with Litchi chinensis (NC_035238) as main reference. Subsequently, Geneious 11.0.4 [58] was used to manually adjusted start and stop codons based on multiple cp genomes of Sapindaceae species. The structural features of cp genome maps were drawn online using OGDRAW [59]. The final cp genomes of Handeliodendron bodinieri and Eurycorymbus cavaleriei were submitted to GenBank of National Center for Biotechnology Information (NCBI), where $H$. bodinieri and $E$. cavaleriei were given MK552107 and MK552106 accession numbers, respectively.

\section{Genome features analysis}

Length of the whole chloroplast genome, numbers of genes, and categories of genes were analyzed in Geneious 11.0.4 [58]. MEGA [60] was adopted to calculate the guanine-cytosine (GC) content. A total of 25 species from Sapindaceae were compared in this analysis, including Aesculus wangii, Ae. chinensis, Acer. buergerianum subsp. ningpoense, A. tataricum subsp. ginnala; A. davidii, A. truncatum, Acer miaotaiense, A. griseum, A. wilsonii, A. sino-oblongum, A. morrisonense, A. palmatum, Dipteronia dyeriana, D. sinensis, Dimocarpus longan, Dodonaea viscosa, Sapindus mukorossi, Xanthoceras sorbifolium, Litchi chinensis, Koelreuteria paniculata, Pometia tomentosa, and Nephelium lappaceum. CodonW software (http://codonw.sourceforge.net/culong.html\#CodonW) was used for analyzing the codon preference. In the current study, all sequences downloaded from NCBI as well as their corresponding GenBank accession numbers are presented in the Table S1.

\section{Dispersed repeats and simple sequence repeats detection} Dispersed repeats, including forward, reverse, palindromic, and complement repeat types, were identified online using REPuter program [61]. The minimal repeat size was limited to no less than $30 \mathrm{bp}$ with the Hamming distance equal to three, and with the other settings retained as default. Furthermore, IR regions are the most typical palindromic repeat sequences in the cp genome, hence were not included in the analysis. The simple sequence repeats (SSRs) of Handeliodendron bodinieri and Eurycorymbus cavaleriei chloroplast genomes were detected using MIcroSAtellite identification tool (MISA) [62]. The parameters were adjusted for the identification of mononucleotide, dinucleotide, tri nucleotide, tetra nucleotide, penta nucleotide and hexa nucleotidemotifs with a minimum of $10,5,4,3,3$, and 3 repeats, respectively.

\section{Whole cp genome sequence comparisons}

The mVISTA program [63] was employed to compare the whole cp genome divergence with related species in Shuffle-LAGAN mode, with the Eurycorymbus cavaleriei chloroplast genome as the reference. To explore the highly divergent regions of the cp genomes in the Sapindaceae species, the software DnaSP version 5.1 [64] was used to calculate nucleotide diversity $(\mathrm{Pi})$. The step size and window length were set as $200 \mathrm{bp}$ and $600 \mathrm{bp}$, respectively. Geneious 11.0.4 [58] was used to detect the contraction/expansion of the inverted repeat regions (IRs), and the final graph of expansions/contractions was visualized using Adobe Illustrator. The genome rearrangement analyses of $H$. bodinieri and $E$. cavaleriei $\mathrm{cp}$ genomes were performed using Mauve with default settings [65].

\section{Selective pressure analysis}

To identify the positive selection sites of protein-coding sequences in the $\mathrm{cp}$ genome, we calculate the non-synonymous $(\mathrm{dN})$ and synonymous $(\mathrm{dS})$ substitution rates using EasyCodeML v1.12 [66]. The analysis was calculated based on four site models (M0 vs. M3, M1a vs. M2a, M7 vs. M8, and M8a vs.M8) with likelihood ratio test (LRT) threshold of $p<0.05$ elucidating adaptation signatures within the genome. Bayes Empirical Bayes (BEB) [67] and Naive Empirical Bayes (NEB) analysis were implemented in the M8 model to detect positive selection sites of the selected genes. Each single-copy CDS sequence was aligned under the codon model and then concatenated into one matrix. Subsequently, the ML tree was constructed using IQ-TREE [68] and then used as an input tree. Due to the lack of sufficient Dodonaeoideae cp genome sequences, the family was divided into two clades to carry out the adaptive evaluation analysis based on the classification of Buerki et al. [17], including Dodonaeoideae+Sapindoideae and Hippocastanoideae.

\section{Phylogenetic analysis}

To ascertain the phylogenetic position of Handeliodendron bodinieri and Eurycorymbus cavaleriei within the Sapindales, a total of 42 species were analyzed, of which 40 complete cp genome sequences were downloaded from NCBI (Table S1). Among these species, Euscaphis japonica in the order Crossosomatales was used as outgroup. Phylogenies were constructed by Maximum Likelihood (ML) and Bayesian Inference (BI) analyses using 


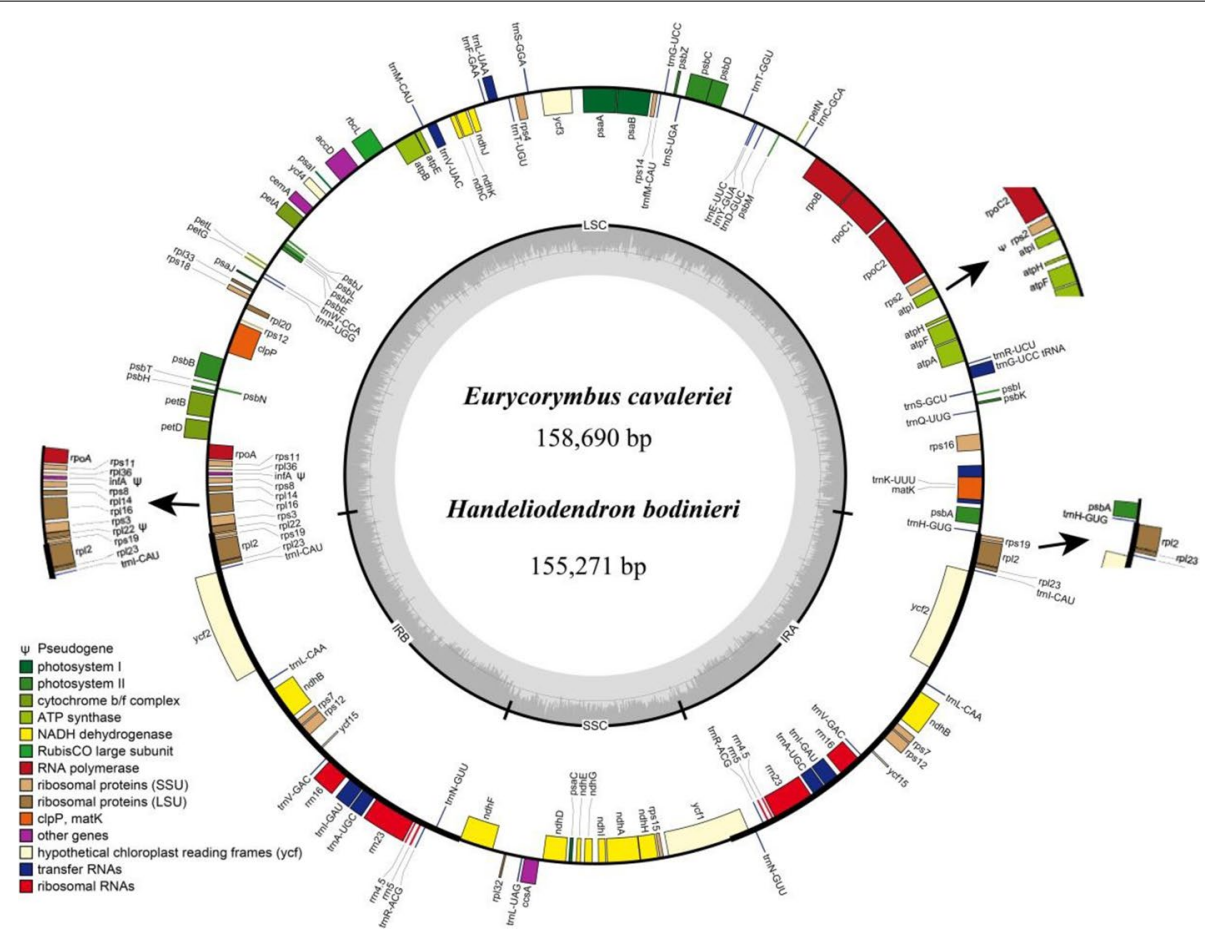

Fig. 1 Circular gene map of chloroplast genomes of Handeliodendron bodinieri and Eurycorymbus cavaleriei. The gray arrowheads indicate the direction of the genes. Genes on the outside and inside of the circle are transcribed in clockwise and counterclockwise directions, respectively. Genes belonging to different functional groups are color coded. The innermost darker gray corresponds to GC content, whereas the lighter gray corresponds to AT content. IR, LSC, SSC indicate inverted repeat, large single copy region, and small single copy region, respectively. The black arrows indicate annotation in H. bodinieri that are inconsistent with those in E. cavaleriei

the complete cp genome sequences, coding sequence (CDS), LSC, SSC, and IR regions. For the CDS dataset, we extracted 79 CDSs using Geneious 11.0.4 [58]. Each CDS matrix was aligned individually by MAFFT [69] with the codon model. All alignments were eventually concatenated into one supermatrix by PhyloSuite [70]. ModelFinder [71] was used to select the best-fit model for constructing phylogenetic tree based on the BIC standard. ML analysis was conducted using IQ-TREE with 1000 bootstrap replicates [68], whereas BI analysis were carried out using MrBayes 3.2.2 [72]. For BI analysis, the two independent Markov Chain Monte Carlo (MCMC) analyses were run for 10,000,000 generations. Trees were sampled every 1000 generations, and the first $25 \%$ of trees generated were discarded as burn-in. Finally, the phylogenetic trees were viewed and edited using Figtree 1.4 (https://github.com/rambaut/figtree).

\section{Results}

\section{General characteristics of the cp genomes}

Chloroplast genome structures of Handeliodendron bodinieri and Eurycorymbus cavaleriei are conserved and their cp genome sizes were 151,271 and 158,690bp, respectively (Fig. 1). Both genomes presented the quadripartite structures including a pair of inverted repeats (IRs) of $25,724 \mathrm{bp}$ and $26,910 \mathrm{bp}$, a large single copy (LSC) region of $85,092 \mathrm{bp}$ and $86,874 \mathrm{bp}$, and a small single copy (SSC) region of $15,812 \mathrm{bp}$ and $17,966 \mathrm{bp}$ in $H$. bodinieri and E. cavaleriei respectively (Table 1 ). In the whole genome, the total GC content of $H$. bodinieri and E. cavaleriei were 37.8 and $37.9 \%$, respectively. Moreover, the GC content was unevenly distributed in the $\mathrm{cp}$ genome of $H$. bodinieri and $E$. cavaleriei. The IR region of $H$. bodinieri showed the highest GC contents (43.1\%), followed by $36.0 \%$ in the LSC region, whereas the SSC region exhibited the lowest GC content of $31.5 \%$. Similarly, the IR region of E. cavaleriei showed higher GC contents (42.8\%) than that of the LSC region (36.1\%) and SSC region (32.3\%). In the coding sequences (CDS), the GC content of $H$. bodinieri and E. cavaleriei were 38.1 and $38.4 \%$, respectively.

A total of 114 unique genes were annotated in $H$. bodinieri and E. cavaleriei, including 77 protein-coding genes (PCGs) in H. bodinieri, whereas 79 PCGs were annotated in E. cavaleriei. 31 tRNA genes and four rRNA genes were annotated in the two species (Table 2). Among these, three genes (infA, rpl22, rpl2) and one gene (infA) had the stop codon appearing prematurely, 
Table 1 Comparison of chloroplast genome feature of Handeliodendron bodinieri and Eurycorymbus cavaleriei

\begin{tabular}{|c|c|c|c|c|c|c|c|}
\hline Species & Location & length (bp) & $\mathrm{T}(\mathrm{U})(\%)$ & C (\%) & A (\%) & G (\%) & $\mathbf{G}+\mathbf{C}(\%)$ \\
\hline \multirow[t]{5}{*}{ H. bodinieri } & LSC & 85,092 & 32.8 & 18.5 & 31.1 & 17.5 & 36.0 \\
\hline & SSC & 18,731 & 34.2 & 16.3 & 34.4 & 15.1 & 31.5 \\
\hline & IR & 25,724 & 28.3 & 20.9 & 28.6 & 22.3 & 43.1 \\
\hline & CDS & 78,970 & 31.4 & 19.5 & 30.5 & 18.6 & 38.1 \\
\hline & Total & 155,271 & 31.5 & 19.3 & 30.6 & 18.6 & 37.8 \\
\hline \multirow[t]{5}{*}{ E. cavaleriei } & LSC & 86,874 & 32.7 & 18.6 & 31.3 & 17.5 & 36.1 \\
\hline & SSC & 17,996 & 33.8 & 16.7 & 33.9 & 15.6 & 32.3 \\
\hline & $\mathbb{I R}$ & 26,910 & 28.5 & 20.8 & 28.6 & 22.1 & 42.8 \\
\hline & CDS & 79,251 & 31.3 & 19.7 & 30.3 & 18.7 & 38.4 \\
\hline & Total & 158,690 & 31.4 & 19.3 & 30.7 & 18.6 & 37.9 \\
\hline
\end{tabular}

Table 2 Summary of assembled gene functions of Handeliodendron bodinieri and Eurycorymbus cavaleriei chloroplast genomes

\begin{tabular}{|c|c|}
\hline Gene Family & Gene Names \\
\hline Subunits of ATP synthase & $\operatorname{atp} A, \operatorname{atp} B, \operatorname{atp} E, \operatorname{atp} F^{*}, \operatorname{atpH}$, atpl \\
\hline Subunits of NADH dehydrogenase & $n d h A^{*}, n d h B^{*}(\times 2), n d h C, n d h D, n d h E, n d h F, n d h G, n d h H, n d h l, n d h J, n d h K$ \\
\hline Subunits of cytochrome & petA, pet $B^{*}$, pet $D^{*}$, petG, petL, petN \\
\hline Subunits of photosystem I & psaA, psaB, psaC, psal, psa」 \\
\hline Subunits of photosystem II & $p s b A, p s b B, p s b C, p s b D, p s b E, p s b F, p s b H, p s b l, p s b J, p s b K, p s b L, p s b M, p s b N, p s b T, p s b Z$ \\
\hline Subunit of rubisco & $r b c L$ \\
\hline Subunit of Acetyl-CoA-carboxylase & $\operatorname{acc} D$ \\
\hline c-type cytochrome synthesis gene & $\operatorname{ccs} A$ \\
\hline Envelop membrane protein & cemA \\
\hline Protease & $c l p P^{* *}$ \\
\hline Translational initiation & $\psi \inf A$ \\
\hline Maturase & matk \\
\hline Large subunit of ribosome & $r p / 2^{*}(\times 2), r p / 14, r p / 16^{*}, r p / 20, r p / 22^{H}, r p / 23(\times 2), r p 32, r p / 33, r p / 36$ \\
\hline DNA dependent RNA polymerase & $r p o A, r p o B, r p o C 1^{*}, r p o C 2$ \\
\hline Small subunit of ribosome & $r p s 2^{H}, r p s 3, r p s 4, r p s 7(\times 2), r p s 8, r p s 11, r p s 12^{* *}(\times 2), r p s 14, r p s 15, r p s 16^{*}, r p s 18, r p s 19(\times E)$ \\
\hline rRNA Genes & $r r n 4.5(\times 2), r r n 5(\times 2), r r n 16(\times 2), r r n 23(\times 2)$ \\
\hline tRNA Genes & 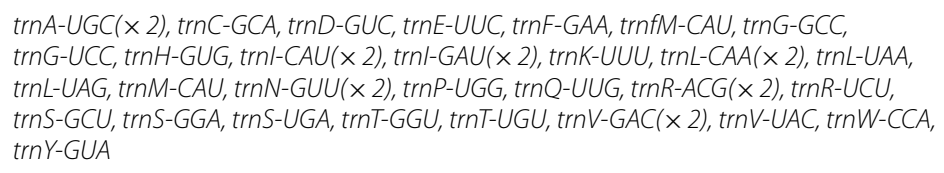 \\
\hline Unknown function & $y c f 1, y c f 2(\times 2), y c f 3^{* *}, y c f 4, y c f 15(\times 2)$ \\
\hline
\end{tabular}

\footnotetext{
* Genes containing a single intron; ** Genes containing two introns; $(\times 2)$ Genes are located within the IR regions and therefore are duplicated; $(\times \mathrm{E})$ Genes present as two copies in the IR regions of $E$. cavaleriei; $\psi$ indicates a pseudogene; ${ }^{H}$ Pseudogene in $H$. bodinieri only
}

thus, were annotated as pseudogenes in $H$. bodinieri and E. cavaleriei, respectively. In total, 18 genes were duplicated in the IR regions of $H$. bodinieri cp genome, including seven tRNA genes (trnA-UGC, trnI-CAU, trnI-GAU , trnL-CAA, trnN-GUU, trnR-ACG, trnV-GAC), four rRNA genes (rrn4.5, rrn5, rrn16, rrn23), and seven PCGs (ndhB, rpl2, rpl23, rps7, rps12, ycf2, ycf15). For the cp genome of $E$. cavaleriei, seven tRNA genes (trnA-UGC, trnI-CAU, trnI-GAU, trnL-CAA, trnN-GUU, trnR-ACG,
trnV-GAC), four rRNA genes (rrn4.5, rrn5, rrn16, rrn23), and eight PCGs (ndhB, rpl2, rpl23, rps7, rps19, rps12, $y c f 2, y c f 15)$ were located in the IR regions.

Among the annotated genes of $H$. bodinieri and $E$. cavaleriei cp genomes, 18 genes contain introns, including atpF, ndhA, ndhB, petB, petD, rpl16, rpl2, rpoC1, rps16, trnV-UAC, trnL-UAA, trnK-UUU, trnI-GAU , trnG-UCC, trnA-UGC, clpP, rps12, and ycf3. Gene $c l p P$, rps12, and $y c f 3$ contain two introns, whereas the 


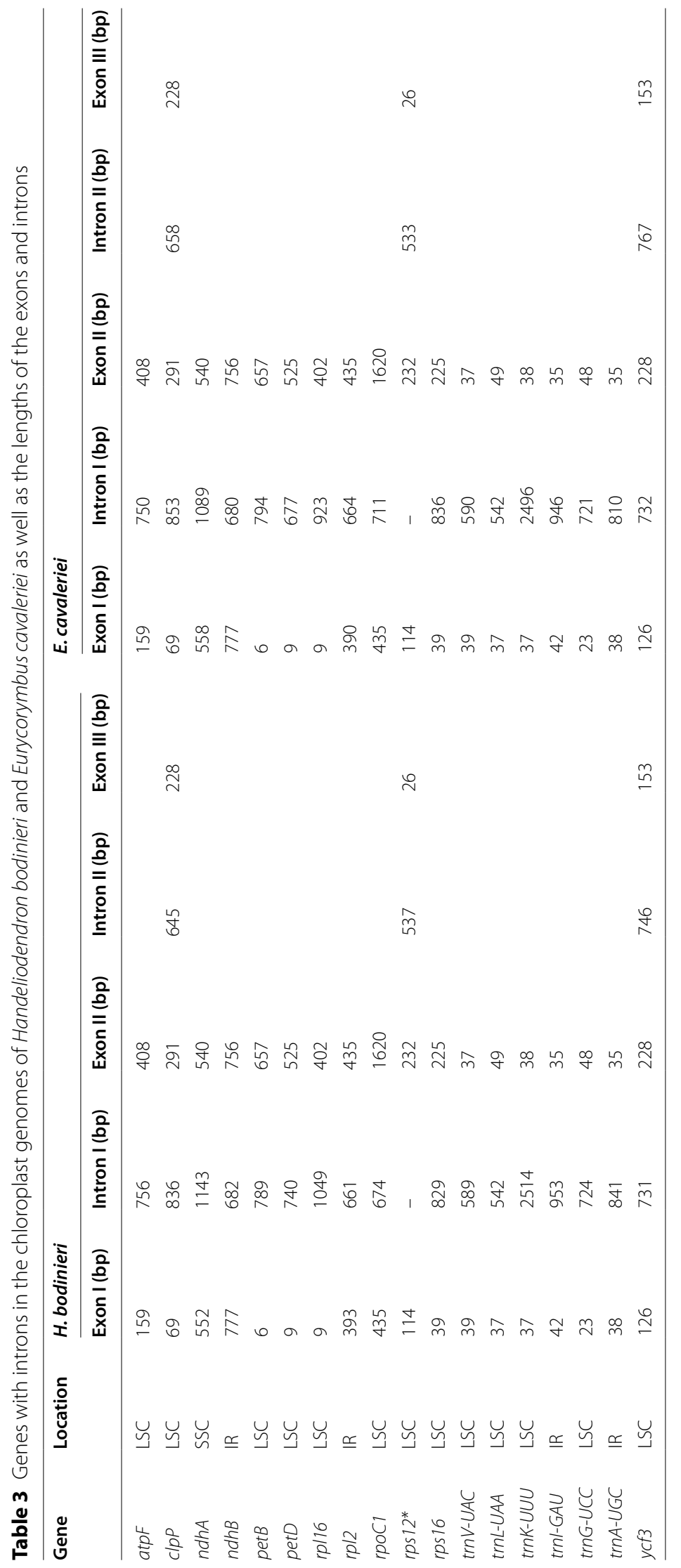


other 15 genes have only one intron (Table 3). Rps 12 is a trans-spliced gene with the $5^{\prime}$ end exon located in the LSC region, but the $3^{\prime}$ end in the IR region, as in most other angiosperms. In addition, the longest intron was detected in trnK-UUU of both cp genomes, and its length was $2514 \mathrm{bp}$ and $2496 \mathrm{bp}$, respectively. Similar to other cp genomes, the matK gene is located in the intron of trnKUUU.

We further compared these basic characteristics of Handeliodendron bodinieri and Eurycorymbus cavaleriei $\mathrm{cp}$ genomes with other genera of Sapindaceae (Table 4). Significantly, we found that the cp genome size of the Hippocastanoideae was generally smaller compared to the other subfamily within Sapindaceae, their size ranged from 152,688 bp (Acer tataricum subsp. ginnala) to $157,367 \mathrm{bp}$ (A. palmatum). Overall, the full-length of $\mathrm{cp}$ genome ranged from 152,688 bp (Acer tataricum subsp. ginnala) to 163,258 bp (Koelreuteria paniculata), but the total GC content was similar among $25 \mathrm{cp}$ genomes of Sapindaceae. By comparing single copy regions, we found that $K$. paniculata possessed the largest LSC region with a length of 90,236 bp, whereas Sapindus mukorossi possessed the largest SSC region $(18,874 \mathrm{bp})$. Among these $\mathrm{cp}$ genomes, the length of IR regions varied from 25,656 bp (Aesculus chinensis) to 30,103 bp (Litchi chinensis). Interestingly, we also discovered $L$. chinensis presenting the smallest SSC region in these cp genomes. This analysis indicated that the number of rRNA is identical, whereas the number of tRNA (from 37 to 40) and PCGs (83-89) were remarkably similar.

\section{Chloroplast repeated sequences and SSRs}

In the current study, a total of 32 and 39 repeat sequences were detected in Handeliodendron bodinieri and Eurycorymbus cavaleriei cp genomes, respectively. In cp genome of $H$. bodinieri, there were 14 forward (F), 1 reverse (R), 16 palindromic $(\mathrm{P})$, and 1 complement $(\mathrm{C})$ repeats (Fig. 2, A). For E. cavaleriei cp genome, the number of the F, R, P, and $C$ repeats was $16,2,20$, and 1 , respectively. We found that the length of repeat sequences ranged from 30 to 51 bp in H. bodinieri, 30-72 bp in E. cavaleriei (Fig. 2, B).

Table 4 Statistics on the basic features of the chloroplast genomes from Sapindaceae species

\begin{tabular}{|c|c|c|c|c|c|c|c|c|}
\hline Species & size (bp) & $\begin{array}{l}\text { LSC } \\
\text { (bp) }\end{array}$ & $\begin{array}{l}\text { IR } \\
\text { (bp) }\end{array}$ & $\begin{array}{l}\text { SSC } \\
\text { (bp) }\end{array}$ & GC content $(\%)$ & No. rRNA & No. tRNA & No. PCGs \\
\hline Acer tataricum subsp. ginnala & 152,688 & 82,529 & 26,306 & 17,795 & 38.2 & 8 & 40 & 87 \\
\hline Handeliodendron bodinieri & 155,271 & 85,092 & 25,724 & 18,731 & 37.8 & 8 & 37 & 89 \\
\hline Aesculus chinensis & 155,528 & 85,489 & 25,656 & 18,727 & 37.9 & 8 & 37 & 83 \\
\hline Aesculus wangii & 155,871 & 84,882 & 26,390 & 18,209 & 38.0 & 8 & 40 & 84 \\
\hline Acer truncatum & 156,262 & 86,018 & 26,086 & 18,072 & 37.9 & 8 & 40 & 89 \\
\hline Acer miaotaiense & 156,595 & 86,327 & 26,100 & 18,068 & 37.9 & 8 & 40 & 89 \\
\hline Acergriseum & 156,857 & 85,227 & 26,742 & 18,146 & 37.9 & 8 & 40 & 86 \\
\hline $\begin{array}{l}\text { Acer buergerianum subsp. } \\
\text { ningpoense }\end{array}$ & 156,911 & 85,314 & 26,752 & 18,093 & 37.9 & 8 & 40 & 89 \\
\hline Acer davidii & 157,044 & 85,410 & 26,761 & 18,112 & 37.9 & 8 & 40 & 86 \\
\hline Acerwilsonii & 157,067 & 85,418 & 26,760 & 18,129 & 37.9 & 8 & 39 & 88 \\
\hline Dipteronia dyeriana & 157,071 & 85,529 & 26,730 & 18,082 & 38.0 & 8 & 40 & 87 \\
\hline Dipteronia sinensis & 157,080 & 85,455 & 26,766 & 18,093 & 37.8 & 8 & 40 & 88 \\
\hline Acer sino-oblongum & 157,118 & 85,558 & 26,722 & 18,119 & 37.9 & 8 & 39 & 88 \\
\hline Acer morrisonense & 157,197 & 85,655 & 26,728 & 18,086 & 37.8 & 8 & 40 & 86 \\
\hline Acerpalmatum & 157,367 & 85,829 & 26,689 & 18,160 & 37.8 & 8 & 40 & 89 \\
\hline Eurycorymbus cavaleriei & 158,690 & 86,874 & 26,910 & 17,996 & 37.9 & 8 & 37 & 87 \\
\hline Dodonaea viscosa & 159,375 & 87,204 & 27,100 & 17,971 & 37.9 & 8 & 37 & 88 \\
\hline Sapindus mukorossi & 160,481 & 85,649 & 27,979 & 18,874 & 37.7 & 8 & 39 & 88 \\
\hline Pometia tomentosa & 160,818 & 85,666 & 28,396 & 18,360 & 37.9 & 8 & 37 & 88 \\
\hline Dimocarpus longan & 160,833 & 85,708 & 28,428 & 18,269 & 37.8 & 8 & 37 & 87 \\
\hline Xanthoceras sorbifolium & 161,231 & 85,299 & 28,620 & 18,692 & 37.7 & 8 & 38 & 86 \\
\hline Nephelium lappaceum & 161,356 & 86,009 & 28,597 & 18,153 & 37.8 & 8 & 37 & 87 \\
\hline Litchichinensis & 162,524 & 85,750 & 30,103 & 16,568 & 37.8 & 8 & 37 & 87 \\
\hline Koelreuteria paniculata & 163,258 & 90,236 & 27,377 & 18,268 & 37.3 & 8 & 37 & 85 \\
\hline
\end{tabular}




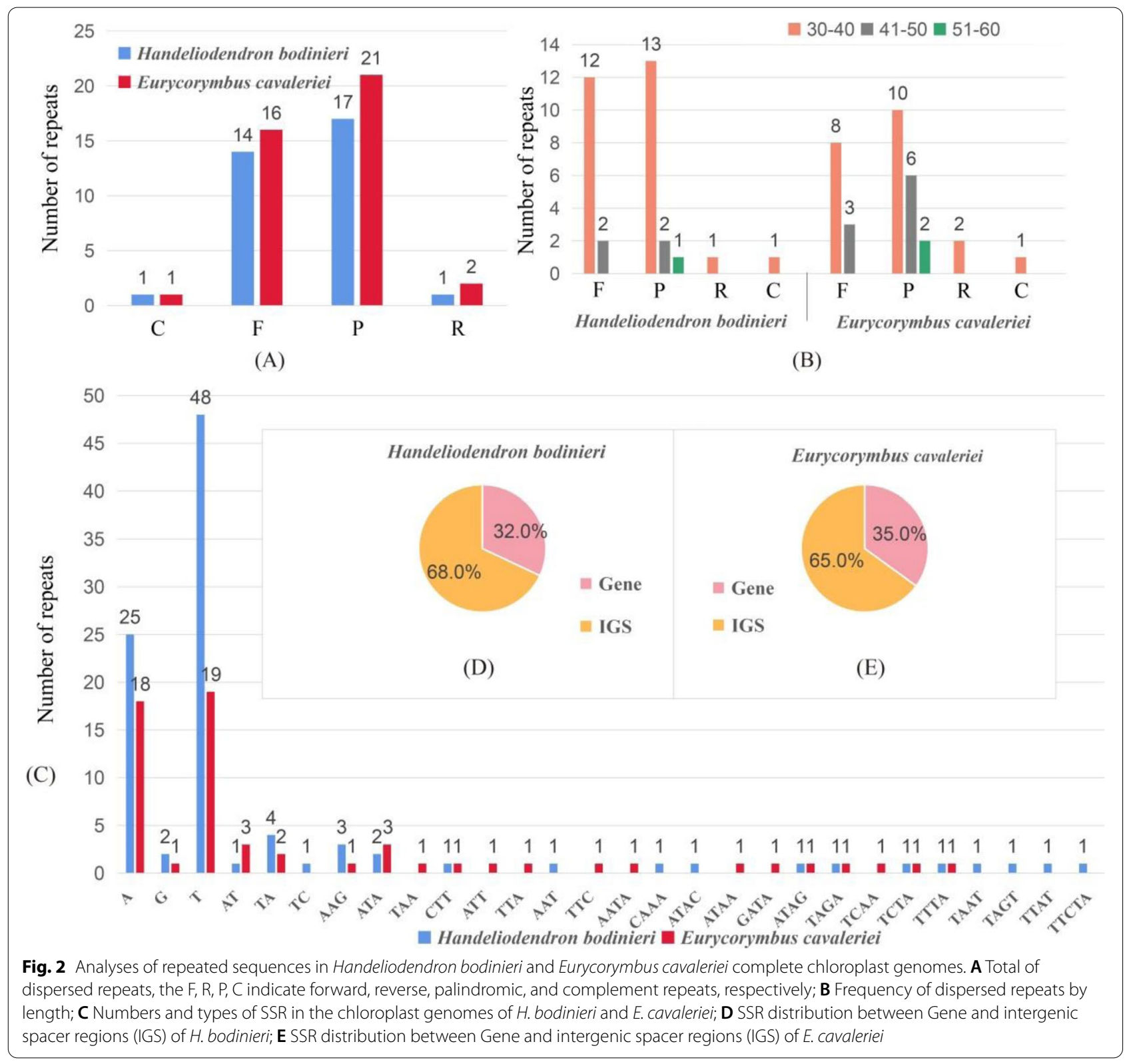

In total, the results revealed that the $\mathrm{P}$ and $\mathrm{F}$ repeats were most abundant in all these repeat sequences, and most of palindromic and forward repeats were with $30-40 \mathrm{bp}$ in length.

Here, we observed the simple sequence repeats of the $H$. bodinieri and E. cavaleriei cp genomes. The total number of the SSRs was 98 in H. bodinieri, whereas 60 in E. cavaleriei (Table S2; Fig. 2, C). In H. bodinieri, we detected five categories of SSRs, including mononucleotide, dinucleotide, tri nucleotide, tetra nucleotide, and penta nucleotide repeats. Additionally, none of hexanucleotides were detected in $H$. bodinieri cp genome. The number of mononucleotide, dinucleotide, tri nucleotide, tetra nucleotide, and penta nucleotide repeats were 75,6 , 7,9 , and 1 , respectively (Fig. 2, C). The finding not only showed that the mononucleotide repeats were the most abundant in the cp genome, but also had an outstanding base preference, mainly consist of A or T. Notably, five SSRs were identified in the $y c f 1$ gene of $H$. bodinieri $\mathrm{cp}$ genome, consisting of mononucleotide repeats that contain four poly (T) and one poly (A). In total, there were four types of SSRs in the E. cavaleriei cp genome, including mononucleotide, dinucleotide, tri nucleotide, and tetra nucleotide repeats (Table S3). The number of mononucleotide, dinucleotide, tri nucleotide, tetra nucleotide, and penta nucleotide repeats were $38,5,8$, 


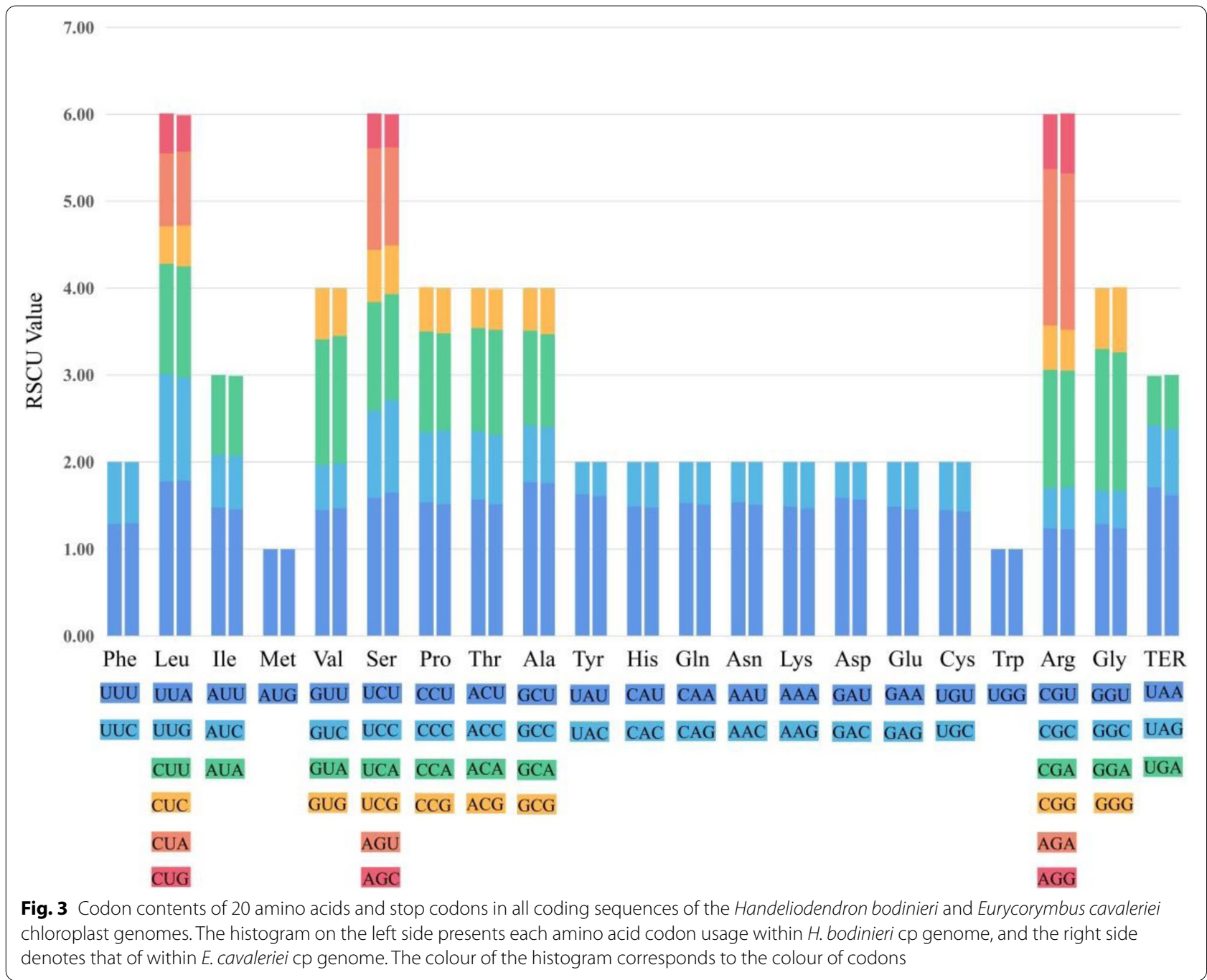

and 8, respectively. Among these SSRs, the most dominant of SSRs were A or T mononucleotides. We also observed four SSRs in the gene $y c f 1$, consist of mononucleotide repeats. Within H. bodinieri and E. cavaleriei cp genomes, most SSRs were located in the intergenic spacer regions (IGS) (Fig. 2, D and E).

\section{Relative synonymous codon usage analysis}

The total number of the codons was 26,028 in Handeliodendron bodinieri, 26,445 in Eurycorymbus cavaleriei. Among the codons, the number of the amino acids less than 1000 was tyrosine (Tyr), glutamine (Gln), histidine (His), methionine (Met), tryptophan (Trp), cysteine (Cys) in both the H. bodinieri (Table S4) and E. cavaleriei (Table S5). The leucine (Leu) was the most amino acid encoded in the analysis, accounting for 10.5 and $10.6 \%$ on average of all amino acids in the $H$. bodinieri and $E$. cavaleriei cp genomes, respectively. However, the Cys has the lowest number of codons in both the H. bodinieri and
E. cavaleriei $\mathrm{cp}$ genomes excluding the stop codons. The codon usage frequency and relative synonymous codon usage (RSCU) were summarized in Fig. 3. In H. bodinieri cp genome, 30 codons had RSCU values more than 1.00, and they all ended with A or U excluding UUG. For the E. cavaleriei, there were 31 codons with RSCU values more than 1.00, 29 of which ended with A or U codons, whereas two ended with $\mathrm{C}$ and G codons (UCC and UUG). Moreover, we discovered that the RSCU values of three codons (AUG, UGG, and UCC) are 1.00 in the $H$. bodinieri cp genome, while only two codons (AUG and UGG) in E. cavaleriei cp genome.

\section{Comparative chloroplast genomic analysis}

To identify the sequence divergence of Handeliodendron bodinieri and Eurycorymbus cavaleriei cp genomes, the genomic rearrangement was detected, with Litchi chinensis as the reference (Fig. 4). In total, $16 \mathrm{cp}$ genomes of 13 genera from Sapindaceae were used for analysis. 


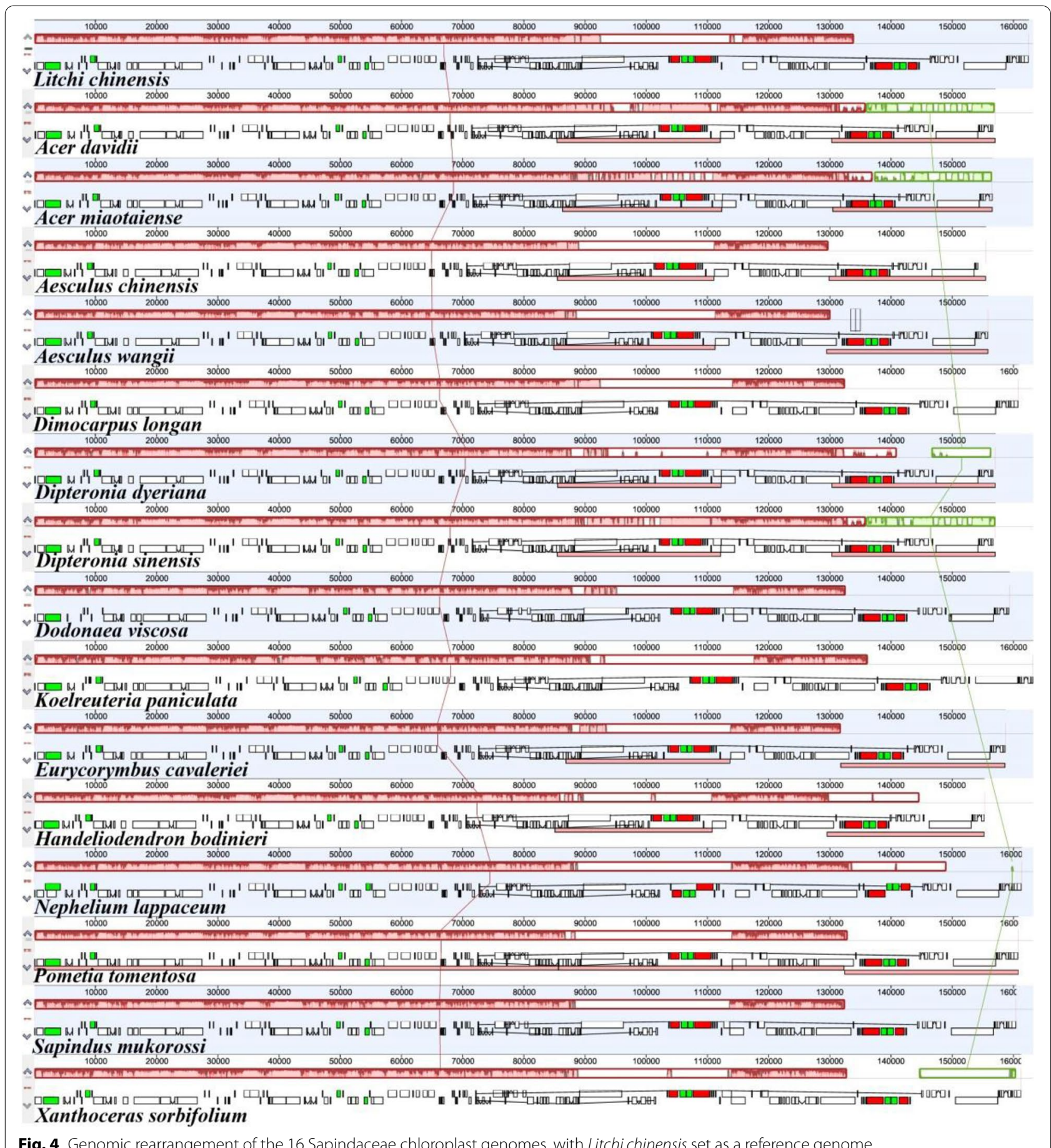

Comparative analysis showed that all $\mathrm{cp}$ genomes were highly conserved, an indication that inversion and translocation in genes or plastid segments was not detected in the final results.

In addition, we performed multiple sequence alignment of the complete chloroplast genome sequences from different families in Sapindales with E. cavaleriei as the reference (Fig. 5). The comparison analyses revealed that coding regions were more conserved than the noncoding regions, and the SSC and LSC regions exhibited more variation than IR regions in all $\mathrm{cp}$ genomes. Moreover, there were almost no variation in four rRNA genes 


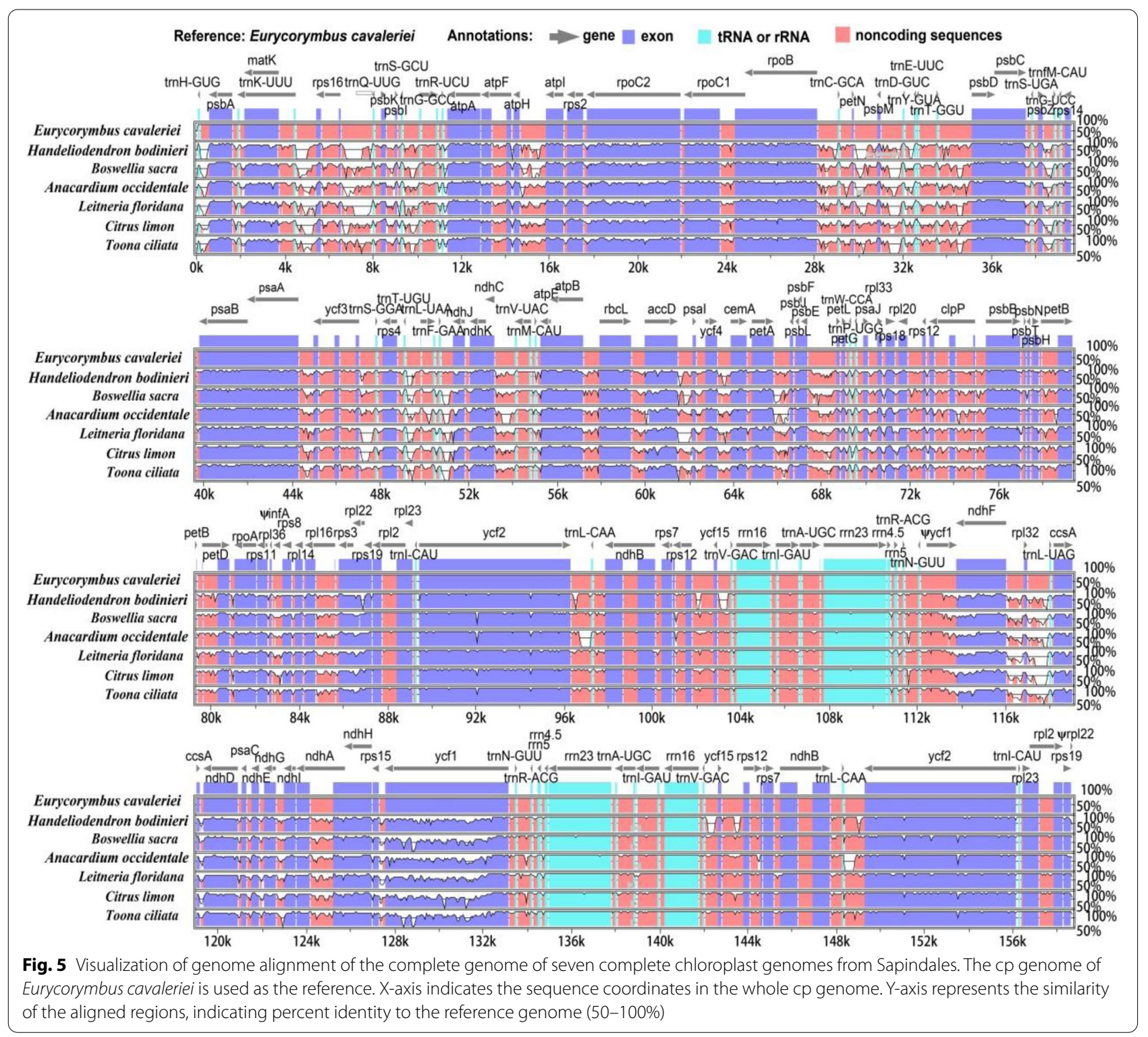

within LSC regions, and the genes were highly conserved. A total of five genes, including matK, accD, $y c f 1, n d h F$, and $r p l 22$, were detected the most divergent in these cp genomes. As shown in Fig. 5, the significant variations were detected in the intergenic regions of the LSC and SSC, including trnH-psbA, trnk-rps16, rps16-trnQ, psbM$\operatorname{trn} Y, p s b Z-\operatorname{trn} G, \operatorname{trnL}$-trnF, trnF-ndhJ, and rpl32-trnL.

\section{Divergence hotspot identification}

To further estimate the divergence of $\mathrm{cp}$ genomes among the Sapindaceae species, a total of $11 \mathrm{cp}$ genome sequences of other genera were chosen randomly to calculate nucleotide diversity (Pi), including Acer davidii, $A$. miaotaiense, Aesculus chinensis, Ae. wangii, Dimocarpus longan, Dipteronia dyeriana, D. sinensis, Dodonaea viscosa, Litchi chinensis, Nephelium lappaceum, Pometia tomentosa, Sapindus mukorossi, and Xanthoceras sorbifolium. Based on this analysis, we identified three remarkably divergent regions among these complete cp genomes, which included ndhC-trnV-UAC, rpl32-trnL-UAG-ccsA, and $y c f 1$ (Fig. 6). Gene $y c f 1$ is the most divergent region with the highest Pi value (0.127) and is located in the SSC region, whereas $n d h C$-trnV-UAC and rpl32-ccsA intergenic spacers were located in LSC regions. These highly divergent regions could be used as potential molecular markers for phylogenetic reconstruction of the family 


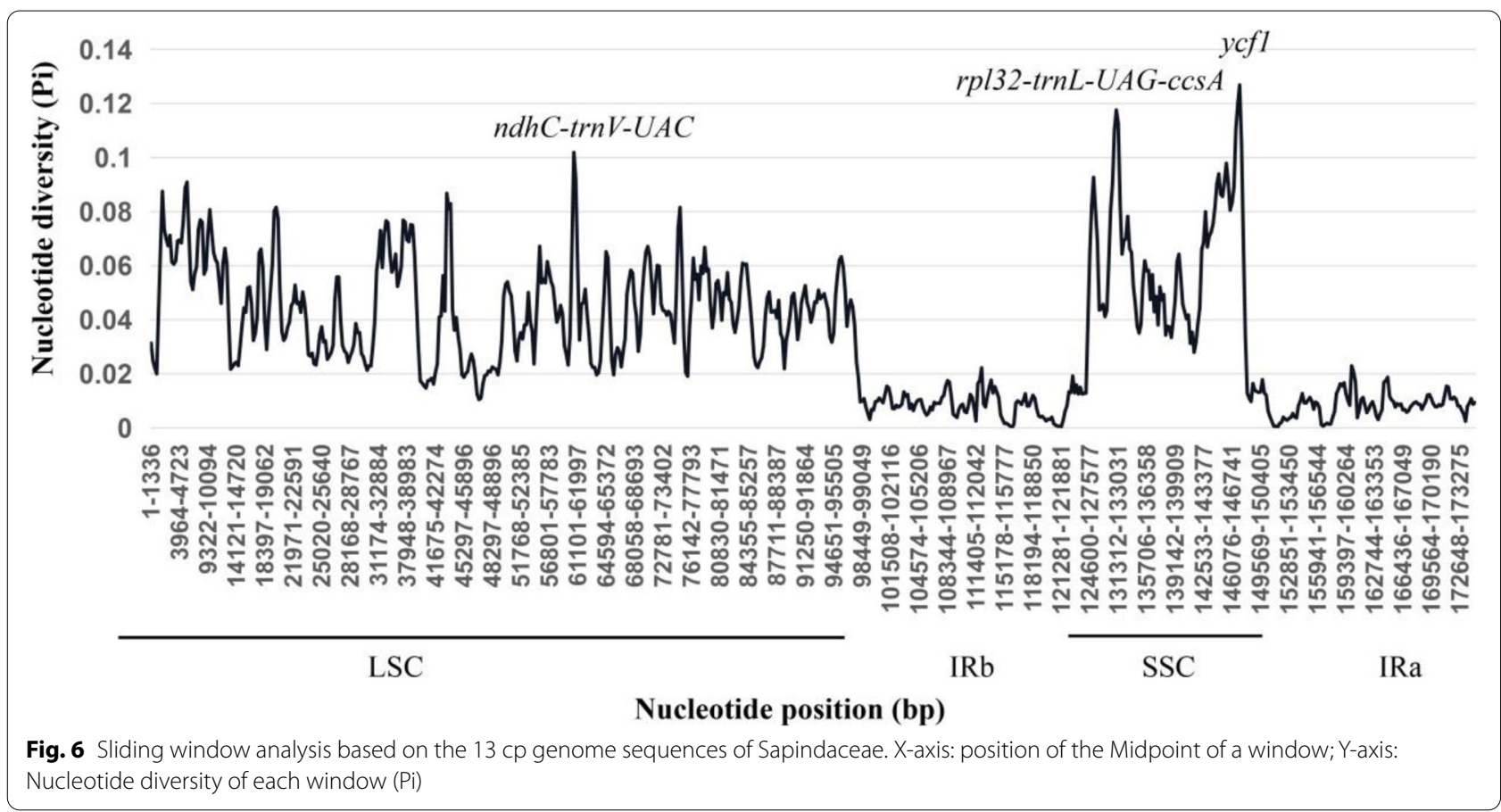

Sapindaceae. Overall, the result of this study revealed that sequence divergence was concentrated in the LSC and SSC regions, whereas IR regions presented less divergence, consistent with the mVISTA results (Fig. 5).

\section{Expansion and contraction of IRs}

We compared the single-copy (SC) and inverted repeat (IR) boundary region among different families within the order Sapindales to find potential evolutionary events. A total of nine cp genomes were chosen randomly, Koelreuteria paniculata (Sapindaceae), Litchi chinensis (Sapindaceae), Leitneria floridana (Simaroubaceae), Toona ciliata (Meliaceae), Anacardium occidentale (Anacardiaceae), Boswellia sacra (Burseraceae), Citrus limon (Rutaceae), as well as our newly sequenced species (Fig. 7). The SSC/IRa boundary located in the coding region of gene $y c f 1$ in all cp genomes, with $2516 \mathrm{bp}$ to $4602 \mathrm{bp}$ in SSC region. The gene $y c f 1$ has the largest fragment in SSC region of $H$. bodinieri. In five cp genomes, including $H$. bodinieri, L. chinensis, T. ciliata, A. occidentale, and C. limon, the gene $n d h F$ spanned IRb/SSC boundary, with $7-36 \mathrm{bp}$ in the IRb region. However, the gene $n d h F$ was wholly located in the IRb region of four cp genomes (E. cavaleriei, K. paniculata, L. floridana, and $B$. sacra), which was separated from the IRb/SSC border by a spacer varying from 0 to $84 \mathrm{bp}$. The gene $y c f 1$ in the border region between IRb and SSC is treated as a pseudogene because of the incomplete duplication of the normal copy. Similarly, rpl22 and rps19 genes in IRa region near the IRa/LSC boundary region, and was annotated as a pseudogene, including E. cavaleriei, K. paniculata, $T$. ciliata, B. sacra, L. floridana, and A. occidentale. In all cp genomes, there was significant variation in the LSC/IRb boundary regions. The LSC/IRb boundary was crossed by the gene $r p l 22$ in five cp genomes, and the length of the rpl22 fragment located in the LSC region ranged from $185 \mathrm{bp}$ (L. floridana) to $449 \mathrm{bp}$ (E. cavaleriei). The rpl 22 was entirely located in the IRb region of $C$. limon $\mathrm{cp}$ genome. In $H$. bodinieri cp genome, rps 19 and $r p l 2$ genes were entirely located within the LSC and IRb region near the LSC/IRb boundary, respectively. In A. occidentale cp genome, we also found that rps19 gene was located in the LSC/IRb boundary, and $178 \mathrm{bp}$ extended into the LSC region. In L. chinensis, the rps 16 and rps3 genes in the near LSC/IRb were located in LSC and IRb regions, respectively. In the IRa/LSC boundary regions, gene trnH was completely located in LSC region of all cp genomes, which was $0-38$ bp away from the IRb/SSC boundary. In a word, IR regions of the $H$. bodinieri showed a significant contraction, whereas it presented a notable expansion in E. cavaleriei cp genome.

\section{Selective pressure analysis}

In the present study, we randomly chose different genera from Dodonaeoideae, Sapindoideae, and Hippocastanoideae. The Dodonaeoideae + Sapindoideae clade contains eight species, including Nephelium lappaceum, Sapindus mukorossi, Litchi chinensis, 


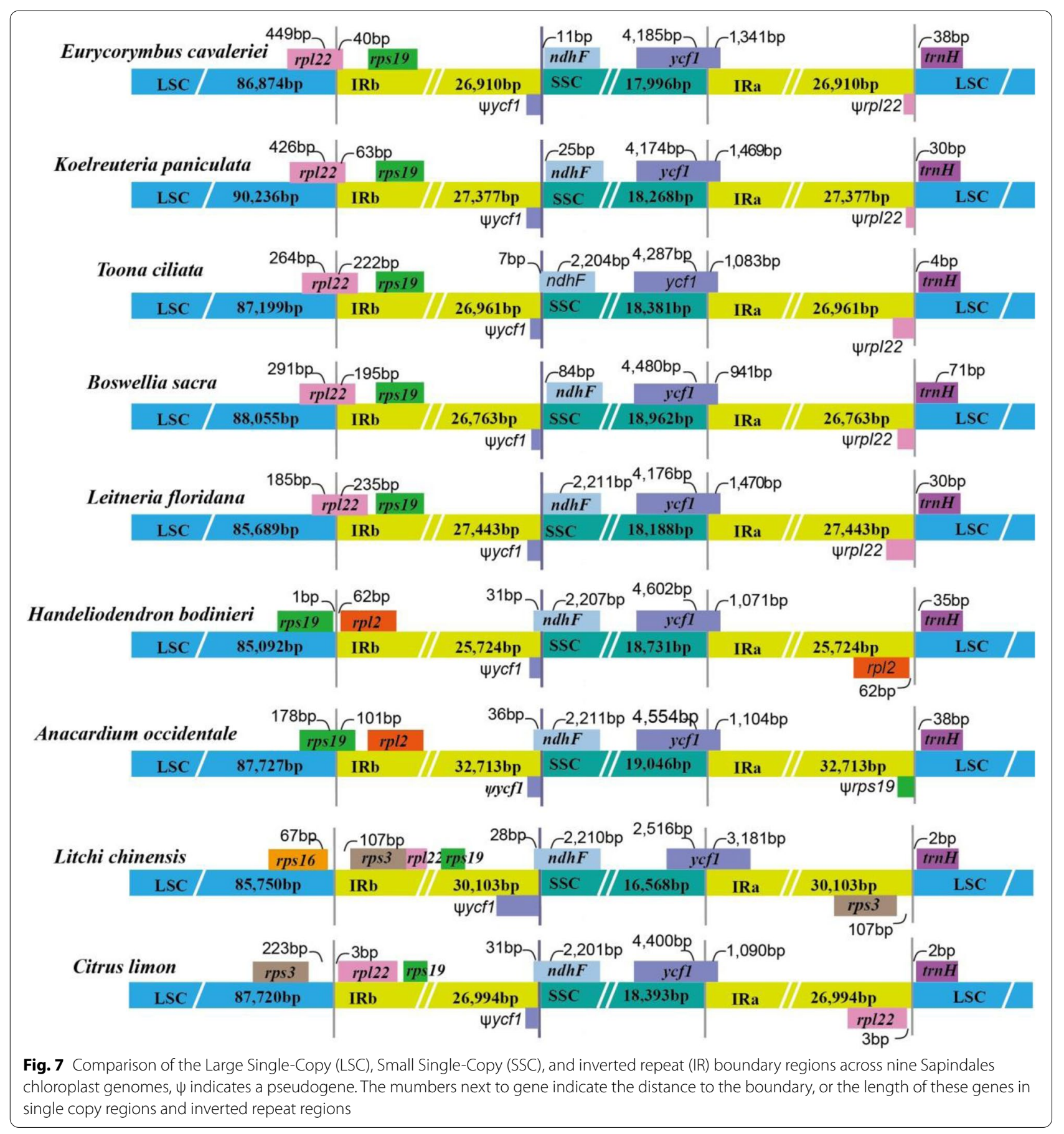

Dodonaea viscosa, Koelreuteria paniculata, Dimocarpus longan, Pometia tomentosa, and Eurycorymbus cavaleriei, while the Hippocastanoideae clade contains five species, including Dipteronia sinensis, Aesculus wangii, Ae. chinensis, Acer morrisonense, and Handeliodendron bodinieri. The analysis of Dodonaeoideae + Sapindoideae clade showed that six genes in the five cp genomes are under significant positive selection
(Table S6), including $c l p P$, ndhF, petA, rpoC1, rpoC2, and rps11. In the NEB method, a total of five genes exhibited under positive selection in the $\mathrm{cp}$ genome of Hippocastanoideae, while the BEB method showed six genes were under significant positive selection (Table S7). In these analyses of Hippocastanoideae and Dodonaeoideae + Sapindoideae, we identified that three sites were detected as sites of positive selection, 


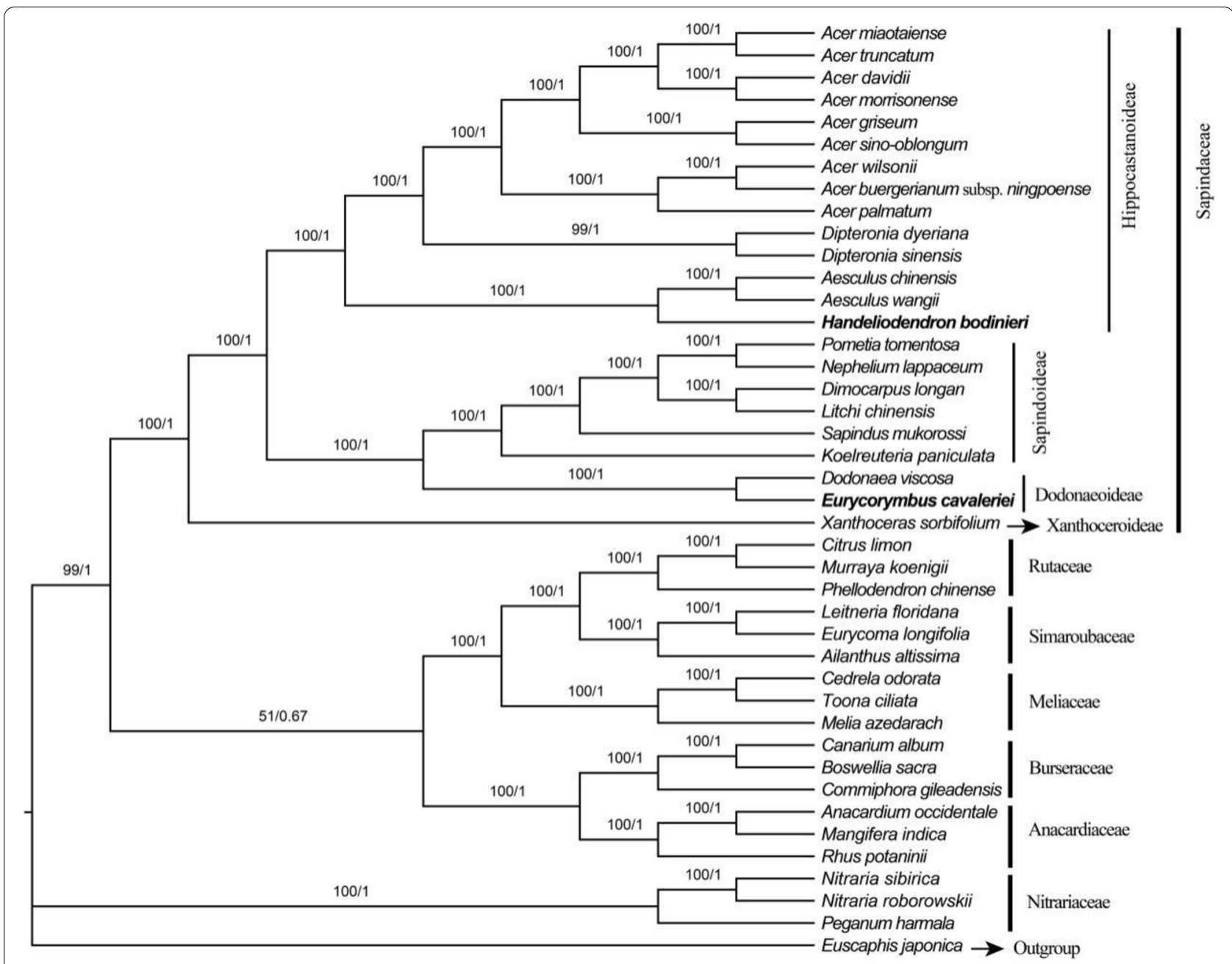

Fig. 8 Phylogenetic tree reconstruction of Sapindales using the maximum likelihood (ML) and Bayesian inference (BI) method based on complete chloroplast genome sequences. Only the ML tree is shown, because its topology is identical to that of the obtained BI tree. ML supports/ BI posterior probabilities values are indicated on the nodes

which were distributed in gene $n d h F$ that related to photosynthesis. In the analysis of Hippocastanoideae, the gene rpoC2 harbored 23 and 32 sites under positive selection according to the NEB and BEB methods, respectively. In addition, we found that the gene $y c f 1$ has ten positive selection sites based upon two methods.

\section{Phylogenetic analysis of Handeliodendron bodinieri and Eurycorymbus cavaleriei within Sapindales}

In this study, phylogenetic analyses were performed based on different datasets, including complete chloroplast genome sequences, coding sequence (CDS), LSC, SSC, and IR regions, with corresponding results in Fig. 8, Fig. 9, Fig. S1, Fig. S2, and Fig. S3, respectively. Detailed information of best-fit model for ML and BI tree are listed in Table S8.
All phylogenetic trees consistently revealed that Handeliodendron bodinieri is sister to the clade consisting of Aesculus chinensis and Aesculus wangii $(\mathrm{BS}=100, \mathrm{PP}=1.00)$, strongly support Eurycorymbus cavaleriei being sister with Dodonaea viscosa $(\mathrm{BS}=100, \mathrm{PP}=1.00)$.

\section{Discussion}

Features of complete chloroplast genome and comparative Analyses

GetOrganelle is a state-of-the-art toolkit to accurately assemble organelle genomes from whole-genome sequencing data [50]. In the current study, GetOrganelle was utilized to assemble the complete chloroplast genome sequences of Handeliodendron bodinieri and Eurycorymbus cavaleriei based on the newly sequenced Illumina data. The total size of $H$. bodinieri cp genome 


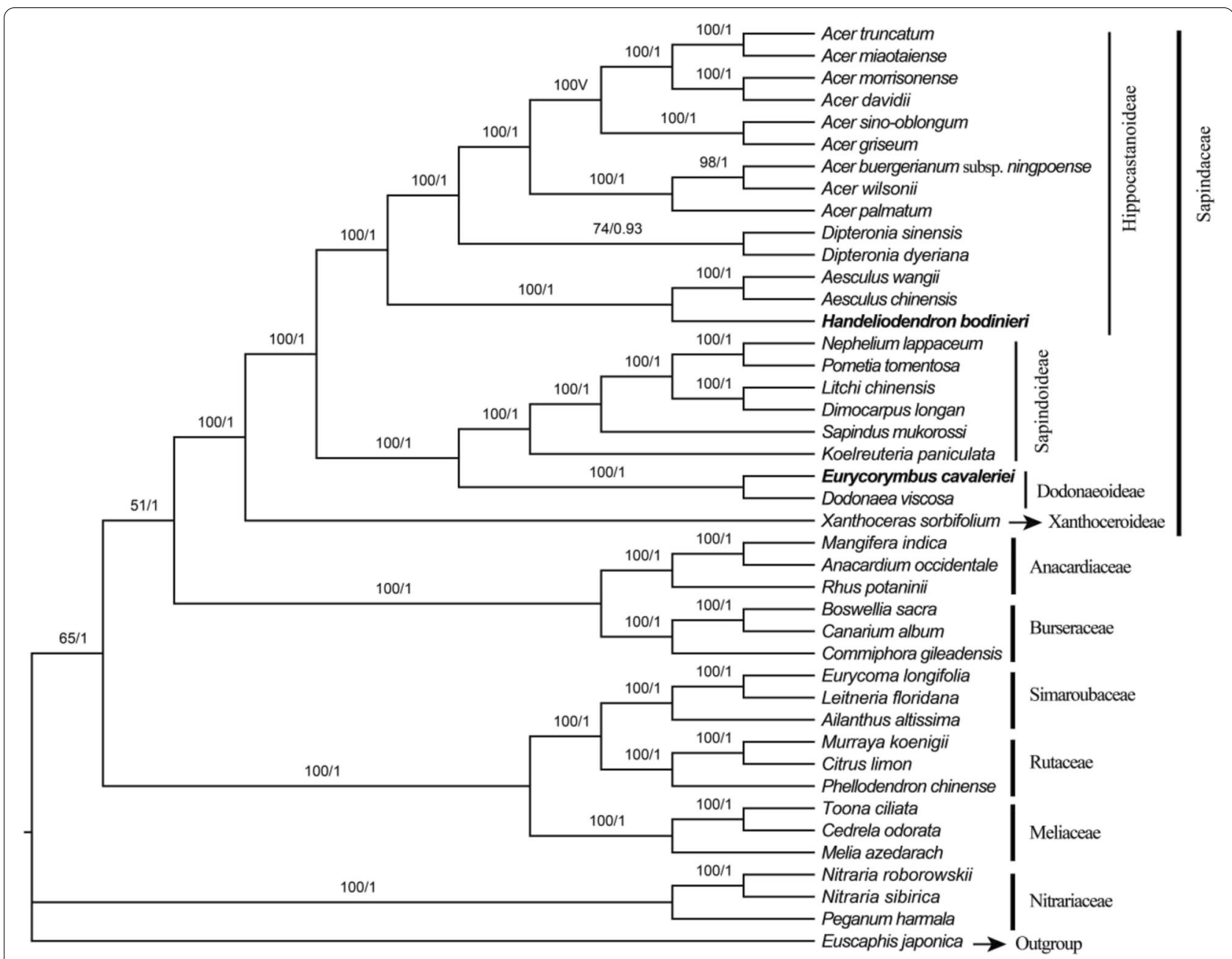

Fig. 9 Phylogenetic tree reconstruction of Sapindales using the maximum likelihood (ML) Bayesian inference (BI) method based on 79 coding sequences. Only the ML tree is shown, because its topology is identical to that of the obtained BI tree. ML supports/BI posterior probabilities values are indicated on the node

is $158,690 \mathrm{bp}$, which is different from the previous reports of Chen et al. [47] and $\mathrm{Du}$ et al. [48]. The fulllength of $H$. bodinieri cp genome is $151,271 \mathrm{bp}$ and is also different from that of the previous report [49]. Their genome exhibited a typical quadripartite structure, including a pair of inverted repeats (IRs), a large single copy (LSC) region, and a small single copy (SSC) region, which was the same as that reported for most other angiosperms [73-75]. This study revealed that gene content and gene order in $H$. bodinieri and E. cavaleriei $\mathrm{cp}$ genomes were quite similar to that of other published Sapindaceae species [76-78]. Additionally, GC content was unevenly exhibited in the cp genome of $H$. bodinieri and E. cavaleriei and the IR region showed higher $\mathrm{GC}$ contents than that of the LSC region and SSC region, which may be attributed to four rRNA genes with low $\mathrm{A} / \mathrm{T}$ content. Within the
$H$. bodinieri and $E$. cavaleriei cp genomes, the clpP, rps 12, and $y c f 3$ genes possess one intron, and 15 genes contain two introns. Pseudogenization of the gene inf $A$ was has been detected in $H$. bodinieri and $E$. cavaleriei $\mathrm{cp}$ genomes, the same results were observed in those of other Sapindaceae species [79-81]. Besides, we detected the pseudogenization of $r p l 22$ and $r p l 2$ genes in $H$. bodinieri cp genome and the latter was also annotated as pseudogene in that of Acer takesimense [82]. A detailed comparative analysis of the complete chloroplast genomes revealed that genomic structure, gene content, PCGs, and total GC content were remarkably similar or identical within 11 genera from Sapindaceae, which were consistent with most studies [83-85]. Significantly, Hippocastanoideae generally have a smaller cp genome size compared to other subfamilies. Considering that not all published $\mathrm{cp}$ genome sequences of 
Sapindaceae species were listed in this table, we further observe all Sapindaceae cp genome sequences in GeneBank database, and the final results supported this finding. However, the work of Luo et al. [86] revealed that the cp genome of Acer coriaceifolium is $159,736 \mathrm{bp}$ in size (Accession: SY9280, it was not be released), and the base composition was asymmetric with an overall GC content of $43.00 \%$. The length of $A$. coriaceifolium $\mathrm{cp}$ genome was bigger than that of published Dodonaeoideae species, which was not consistent with the above finding. Meanwhile, we also found that there are three $A$. coriaceifolium cp genome sequences with $155,944 \mathrm{bp}$ in the GeneBank database (Accession: MW067038, NC_050669, and MN315271). Overall, the Hippocastanoideae species have a smaller cp genome size and exhibit a close relationship to some extent, although this finding should be tested further with sufficient sampling.

The study demonstrated that palindromic (P) and forward $(F)$ repeats were the most abundant in all dispersed repeats, and most of them were $30-40 \mathrm{bp}$ in length, similar to previous studies [33,87-89]. Simple sequence repeats (SSRs) were widely used as a molecular marker for studies of genetic diversity and population structure [90-92]. We observed five and four types of SSRs in $H$. bodinieri and $E$. cavaleriei $\mathrm{cp}$ genomes, respectively. Among these SSRs, the most dominant of SSRs were A or T mononucleotides. Furthermore, most of SSRs were in the intergenic spacer regions (IGS), which is consistent with other studies $[80,93]$. The finding not only showed that the mononucleotide repeats were the most abundant in the cp genome but also had an $\mathrm{A} / \mathrm{T}$ base preference.

Within Handeliodendron bodinieri and Eurycorymbus cavaleriei coding sequences, the leucine (Leu) was the frequent amino acid, while the least abundant amino was cysteine (Cys) excluding the stop codons. Moreover, the findings of this study revealed that most codons ended with A or U when RSCU values more than 1.00. As a common phenomenon in cp genomes of plants, similar results have been reported in previous studies [74, 94-96].

The mVISTA results revealed that coding regions were more conserved than the non-coding regions, and the SSC and LSC regions exhibited more variation than IR regions in all $\mathrm{cp}$ genomes. The results of this study are consistent with previous finings in other species [29, $75,76,97]$. In total, we identified five genes present significant variations in these cp genomes, such as matK, $a c c D, y c f 1, n d h F$, and $r p l 22$. Additionally, eight intergenic regions, namely trnH-psbA, trnk-rps16, rps16-trnQ, psbM-trnY, psbZ-trnG, trnL-trnF, trnF-ndhJ, and rpl32trnL also present significant variations. The nucleotide diversity tests indicate IR regions showed relatively low diversity, but we found ndhC-trnV-UAC, rpl32-trnL$U A G-c c s A$, and $y c f 1$ were remarkably divergent regions in LSC and SSC regions, which could be used as the specific DNA barcodes for Sapindaceae species. Gene $y c f 1$ was a high variable genic region in cp genome of plants $[23,73$, 94], which has abundant SSRs in our newly sequenced species.

Up to date, cp genome sequences of 13 genera from Sapindaceae are deposited in GenBank database (Table 4). Comparative analysis showed that Handeliodendron bodinieri and Eurycorymbus cavaleriei cp genomes exhibited highly conserved, and the phenomenon of inversion and translocation in genes or plastid segments was not detected in both species. The border regions of $\mathrm{cp}$ genome quadripartite structure exhibited expansion and contraction variation, which were common phenomenons in the evolutionary history of land plants [96]. We found that there some significant variation in LSC and IR boundary regions. In the family Sapindaceae, the LSC/IRb boundary was traversed by the gene $r p l 22$ in four cp genomes, but it is different from those of $H$. bodinieri and Litchi chinensis. Interestingly, their boundaries were similar to that of the member of Simaroubaceae (Leitneria floridana). We noticed that IRa/LSC boundary regions showed some differences, but gene $\operatorname{trnH}$ was completely located in LSC region of all cp genomes. In different families, the SSC/IRa and IRb/ SSC boundary regions exhibit highly conserved, which resembles most previous studies [98-100]. The pseudogenes, $y c f 1$ and $r p l 22$ were present at the IRb/SSC and $\mathrm{IRa} / \mathrm{LSC}$ boundaries of $E$. cavaleriei cp genome, respectively, because the incomplete duplication of the normal copy. The finding revealed the IR boundary regions of $E$. cavaleriei $\mathrm{cp}$ genome are similar to the $K$. paniculata, $T$. ciliata, B. sacra, and L. floridana, while the IR boundary regions of $H$. bodinieri cp genome resemble that of other reported Acer species (Acer miaotaiense, A. sterculiaceum, $A$. amplum) $[46,80]$. IR regions of the $H$. bodinieri and $E$. cavaleriei cp genomes showed noticeable contraction and expansion, respectively. The non-synonymous $(\mathrm{dN})$ and synonymous $(\mathrm{dS})$ substitution rates are useful for inferring the adaptive evolution of genes [24, 101, 102]. We compared different genera from three subfamilies, and the analysis of selection pressure showed that there are a few positively selected genes, which are essential in unfolding evolutionary history of these genera.

\section{Phylogenetic analysis}

Phylogenetic analysis based on different datasets consistently demonstrated that Handeliodendron bodinieri was sister to the clade that consisted of Aesculus chinensis and $A$. wangii $(\mathrm{PP}=1.00, \mathrm{BS}=100)$. On the basis of plastid matK and $r b c L$ DNA sequences, the work of 
Harrington et al. [15] strongly supported $H$. bodinieri was sister to Aesculus plus Billia. Subsequently, based on a combination of nuclear (ITS) and plastid (matK, rpoB, trnD-trnT, trnK-matK, trnL-trnF, and trnS-trnG) markers, Buerki et al. [18] suggested the possible paraphyly of the Aesculus because Handeliodendron and Billia were nested within it. Our results strongly supported that $H$. bodinieri had a close relationship with the Aesculus, which was consistent with the works of Harrington et al. [15] and Buerki et al. [18]. However, the present analyses could not demonstrate the paraphyly of the Aesculus because of lacking sufficient samples. In this study, we found Eurycorymbus cavaleriei as sister to Dodonaea viscosa with strong support $(\mathrm{PP}=1.00, \mathrm{BS}=100)$, which similar to previous studies [45, 47, 48, 76, 84]. Buerki et al. $[17,18]$ conducted molecular phylogenetic studies of Sapindaceae s. lat. Based on comprehensive sampling. Their results demonstrated that Eurycorymbus belongs to a member of the Dodoneae group within Dodonaeoideae, strongly supported Euphorianthus longifolius as sister to E. cavaleriei, but the E. longifolius was not sampled here. Furthermore, for the Sapindaceae, it remains ambiguous in terms of the phylogenetic relationship to other members within Sapindales. In whole cp genome analysis, Sapindaceae formed a sister of the Rutaceae + Simaroubaceae + Meliaceae + Burseraceae + Anacardiaceae clade ( $\mathrm{BS}=99, \mathrm{PP}=1$, Fig. 9), but the clade consist of Rutaceae + Simaroubaceae + Meliaceae + Burseraceae + Anacardiaceae was weakly supported $(\mathrm{BS}=51, \mathrm{PP}=0.67)$. In the CDS analysis, Sapindaceae was sister to Anacardiaceae and Burseraceae with weak support ( $\mathrm{BS}=51, \mathrm{PP}=1$, Fig. 9), the result is consistent with previous studies $[99,103]$. In the LSC analysis, Sapindaceae was sister to the Burseraceae + Anacardiaceae + Nitrariaceae clade $(\mathrm{BS}=49, \mathrm{PP}=0.99$, Fig. $\mathrm{S} 1)$, In the SSC analysis, Sapindaceae was sister to the Rutaceae + Simaroubaceae + Meliaceae clade $(B S=52, P P=1$, Fig. S2), which is similar to the previous work $[84,85]$. Overall, as the sister group of Sapindaceae, most results exhibited weak support in maximum likelihood analysis. This work will contribute to a comprehensive understanding of plastome evolution in Sapindaceae species and provide valuable chloroplast genomic information for further elucidating the circumscription of Sapindaceae at the cp genome level.

\section{Conclusion}

In this work, we sequenced and assembled the complete chloroplast genome of Handeliodendron bodinieri and Eurycorymbus cavaleriei. Their gene order, gene content, and molecular structure are similar to that of cp genomes of other Sapindaceae species. Comparative analysis of complete $\mathrm{cp}$ genomes revealed that the $\mathrm{cp}$ genome size of the Hippocastanoideae was generally smaller across Sapindaceae. We detected three highly divergent regions, which could be used as the specific DNA barcodes within Sapindaceae. Phylogenetic results consistently confirm that $H$. bodinieri has a close relationship with the genus Aesculus, strongly support E. cavaleriei as sister to Dodonaea viscosa. As the national-level protected species, both $H$. bodinieri and E. cavaleriei attract scientific attention in many aspects, thus this work will provide valuable chloroplast genomic information, and contribute to facilitating future studies in population genetics and conservation biology.

\section{Abbreviations}

LSC: large single copy; SSC: small single copy; IR: inverted repeat; BI: Bayesian inference; ML: Maximum Likelihood; PCGs: protein-coding genes; rRNA: Ribosomal RNA; SSR: simple sequence repeats; tRNA: Transfer RNA; cp: chloroplast; CTAB: cetyltrimethylammonium bromide; CDS: coding sequence; RSCU: Relative synonymous codon usage.

\section{Supplementary Information}

The online version contains supplementary material available at https://doi. org/10.1186/s12864-021-08259-w.

Additional file 1: Table S1. All sequences that were used for understanding the phylogenetic analysis within Sapindales, including their corresponding CDS information and GenBank accession numbers.

Additional file 2: Table S2. Simple sequence repeats (SSRs) in the Handeliodendron bodinieri chloroplast genome.

Additional file 3: Table S3. Simple sequence repeats (SSRs) in Eurycorymbus cavaleriei chloroplast genome.

Additional file 4: Table S4. Relative synonymous codon usage (RSCU) of Handeliodendron bodinieri chloroplast genome.

Additional file 5: Table S5. Relative synonymous codon usage (RSCU) of Eurycorymbus cavaleriei chloroplast genome.

Additional file 6: Table S6. Positive selected sites detected in the cp genome of the Dodonaeoideae + Sapindoideae. Table S7. Positive selected sites detected in the cp genome of the subfamily Hippocastanoideae.

Additional file 7: Table S8. Best-fit Models in ML and BI analysis.

Additional file 8: Figure S1. Phylogenetic tree reconstruction of Sapindales using the maximum likelihood $(\mathrm{ML})$ and Bayesian inference (BI) method based on large single copy ( $\mathrm{LSC}$ ) region. Only the ML tree is shown, because its topology is identical to that of the obtained $\mathrm{BI}$ tree. $\mathrm{ML}$ supports/BI posterior probabilities values are indicated on the nodes.

Additional file 9: Figure S2. Phylogenetic tree reconstruction of Sapindales using the maximum likelihood (ML) and Bayesian inference (BI) method based on inverted repeat (IR) region. Only the $M L$ tree is shown, because its topology is nearly identical to that of the obtained $B /$ tree. $M L$ supports/BI posterior probabilities values are indicated on the nodes. "-" indicates that the node is incongruent between the topology of the ML tree and the Bayesian tree.

Additional file 10: Figure S3. Phylogenetic tree reconstruction of Sapindales using the maximum likelihood (ML) and Bayesian inference (BI) method based on small single copy (SSC) region. Only the ML tree is shown, because its topology is identical to that of the obtained $\mathrm{BI}$ tree. ML supports/BI posterior probabilities values are indicated on the nodes. 


\section{Acknowledgements \\ Not applicable.}

\section{Authors' contributions}

HGX collected these materials and identified species. HGX designed the experiments and organized the manuscript. YJX and HGW performed the analyses. YJX wrote the manuscript. All authors read and approved the final manuscript.

\section{Funding}

This study got financial support from grants from National Science \& Technology Fundamental Resources Investigation Program of China (Grant No. 2019FY101800), National Natural Science Foundation of China (31970211), and Sino-Africa Joint Research Center, CAS (SAJC202101).

\section{Availability of data and materials}

All data generated or analyzed during this study are included in this published article and the complete chloroplast genome sequences of Handeliodendron bodinieri and Eurycorymbus cavaleriei are deposited in the genbank with ID no: MK552107 and MK552106, respectively. The accession numbers corresponding to the additional datasets used and analyzed in this study can be found in Table S1. These were retrieved from National Center for Biotechnology Information database.

\section{Declarations}

\section{Ethics approval and consent to participate}

The authors have complied with the relevant institutional, national and international guidelines in collecting biological materials for the study. Collection permits for materials for sequencing were granted by the Guizhou Academy of Sciences and Guizhou Forestry Bureau, Guizhou province, China. The study contributes to facilitating future studies in population genetics and conservation biology.

\section{Consent for publication}

Not applicable.

\section{Competing interests}

The authors declare that they have no competing interests.

\section{Author details}

${ }^{1}$ Core Botanical Gardens/Wuhan Botanical Garden, Chinese Academy of Sciences, Wuhan 430074, China. ${ }^{2}$ Sino-Africa Joint Research Center, Chinese Academy of Sciences, Wuhan 430074, China. ${ }^{3}$ University of Chinese Academy of Sciences, Beijing 100049, China. ${ }^{4}$ College of Life Sciences, Guizhou University, Guiyang 550025, Guizhou, China.

Received: 18 August 2021 Accepted: 13 December 2021

Published online: 06 January 2022

\section{References}

1. Luo, X.R., Chen, D.Z., Flora Reipublicae Popularis Sinicae, Sapindaceae. Vol. 47. 1985, Beijing: Science Press. 4-72.

2. Cao LM, Teng T, Wu YX, Cao M. Physicochemical property and fatty acid composition of Eurycorymbus cavaleriei (Sapindaceae) seed oil. China Oils and Fats. 2014;39(8):95-7.

3. Cao LM, Wang YH, Zhao C, Zou BB. Analysis on nutrient components of seed kernel of Eurycorymbus cavaleriei. J Plant Resour Environ. 2015;24(4):114-5.

4. Chen XX, Xuan XX, Qiu LF, Wei YY, Qin JL. Handeliodendron Rehder, a newly recorded genus of the family Sapindaceae in Yunnan Province. J Southwest Forestry University (Natural Sciences). 2017;30(3):85-7.

5. Xia, N.H., Gadek, P.A., Eurycorymbus, in Flora of China. 2007, Science Press \& Missouri Botanical Garden Press: Beijing \& St. Louis p 8.

6. Radlkofer L. Sapindaceae. In: Engler A, editor. Das Pflanzenreich IV, 165 (Heft 98a-h). Leipzig: Werlag von Wilhelm Engelmann; 1933.

7. Radlkofer L. Uber die Gliederung der Familie der Sapindaceen. Sitz -Ber Akad Wiss Munchen. 1890:20:105-379.
8. Muller, J., Leenhouts, P.W., A general survey of pollen types in Sapindaceae in relation to taxonomy. In: Ferguson, I.K, Müller, J. (Eds.), the evolutionary significance of the exine. Linnean Soc. Symp. Ser. 1, pp. 407-445. London: Academic Press. 1976.

9. Dahlgren G. An updated angiosperm classification. Bot J Linn Soc. 1989;100:197-203.

10. Cronquist, A., The evolution and classification of flowering plants. 1988, New York Botanic Gardens: New York.

11. Takhtajan A. Systema Magonoliophytorum. Leningrad: Soviet Sciences Press; 1987

12. Umadevi I, Daniel M. Chemosystematics of the Sapindaceae. Feddes Repertorium. 1991;102(7-8):607-12. https://doi.org/10.1002/fedr.19911 020711.

13. Judd WS. Angiosperm family pairs: preliminary phylogenetic analyses. Harvard Pap Bot. 1994;5:1-51.

14. Thorne RF. The classification and geography of the flowering plants: Dicotyledons of the class angiospermae (subclasses magnoliidae, ranunculidae, caryophyllidae, dilleniidae, rosidae, asteridae, and lamiidae). Bot Rev. 2000;66(4):441-647. https://doi.org/10.2307/4354381.

15. Harrington MG, Edwards KJ, Johnson SA, Chase MW, Gadek PA. Phylogenetic inference in Sapindaceae sensu lato using plastid matK and rbcL DNA sequences. Syst Bot. 2005;30(2):366-82. https://doi.org/10. 1600/0363644054223549.

16. Thorne RF, Reveal JL. An updated classification of the class Magnoliopsida ("Angiospermae"). Bot Rev. 2007;73(2):67-182. https://doi.org/10. 1663/0006-8101(2007)73[67:AUCOTC]2.0.CO;2.

17. Buerki S, Forest F, Acevedo-Rodriguez P, Callmander MW, Nylander JA, Harrington $\mathrm{M}$, et al. Plastid and nuclear DNA markers reveal intricate relationships at subfamilial and tribal levels in the soapberry family (Sapindaceae). Mol Phylogenet Evol. 2009;51(2):238-58. https://doi.org/ 10.1016/j.ympev.2009.01.012.

18. Buerki S, Lowry PP, Alvarez N, Razafimandimbison SG, Küpfer P, Callmander MW. Phylogeny and circumscription of Sapindaceae revisited: molecular sequence data, morphology and biogeography support recognition of a new family, Xanthoceraceae. Plant Ecol Evol. 2010;143(2):148-59. https://doi.org/10.5091/plecevo.2010.437.

19. APGIV. An update of the angiosperm phylogeny group classification for the orders and families of flowering plants: APG IV. Bot J Linn Soc. 2016;181(1):1-20.

20. Rehder A. Handeliodendron, a new genus of sapindaceae. J Arnold Arboretum. 1935;16(1):65-7.

21. Xia, N.H., Turland, N.J., Gadek, P.A., Handeliodendron, in Flora of China. 2007, Science Press \& Missouri Botanical Garden Press: Beijing \& St. Louis. 1-2.

22. Zhang R, Wang YH, Jin JJ, Stull GW, Bruneau A, Cardoso D, et al. Exploration of plastid Phylogenomic conflict yields new insights into the deep relationships of Leguminosae. Syst Biol. 2020;69(4):613-22. https://doi. org/10.1093/sysbio/syaa013.

23. Kim GB, Lim CE, Kim JS, Kim K, Lee JH, Yu HJ, et al. Comparative chloroplast genome analysis of Artemisia (Asteraceae) in East Asia: insights into evolutionary divergence and phylogenomic implications. BMC Genomics. 2020;21(1):415. https://doi.org/10.1186/s12864-020-06812-7.

24. Xie DF, Tan JB, Yu Y, Gui LJ, Su DM, Zhou SD, et al. Insights into phylogeny, age and evolution of Allium (Amaryllidaceae) based on the whole plastome sequences. Ann Bot. 2020;125(7):1039-55. https://doi.org/10. 1093/aob/mcaa024

25. Yan M, Fritsch PW, Moore MJ, Feng T, Meng A, Yang J, et al. Plastid phylogenomics resolves infrafamilial relationships of the Styracaceae and sheds light on the backbone relationships of the Ericales. Mol Phylogenet Evol. 2018;121:198-211. https://doi.org/10.1016/j.ympev. 2018.01.004.

26. Zhao F, Chen YP, Salmaki Y, Drew BT, Wilson TC, Scheen AC, et al. An updated tribal classification of Lamiaceae based on plastome phylogenomics. BMC Biol. 2021;19(1):2. https://doi.org/10.1186/ s12915-020-00931-z.

27. Wang, Y.H., Qu, X.J., Chen, S.Y., Li, D.Z., Yi, T.S. Plastomes of Mimosoideae: structural and size variation, sequence divergence, and phylogenetic implication. Tree Genet Genomes, 2017; 13(2). https://doi.org/10.1007/ s11295-017-1124-1.

28. Liu BB, Liu GN, Hong DY, Wen J. Eriobotrya belongs to Rhaphiolepis (Maleae, Rosaceae): evidence from chloroplast genome and nuclear 
ribosomal DNA data. Front Plant Sci. 2019;10:1731. https://doi.org/10. 3389/fpls.2019.01731.

29. Wang JH, Moore MJ, Wang H, Zhu ZX, Wang HF. Plastome evolution and phylogenetic relationships among Malvaceae subfamilies. Gene. 2021;765:145103. https://doi.org/10.1016/j.gene.2020.145103.

30. Cai CN, Ma H, Ci XQ, Conran JG, Li J. Comparative phylogenetic analyses of Chinese Horsfieldia (Myristicaceae) using complete chloroplast genome sequences. J Syst Evol. 2020. https://doi.org/10.1111/jse.12556.

31. Teshome GE, Mekbib Y, Hu GW, Li ZZ, Chen JM. Comparative analyses of 32 complete plastomes of Tef (Eragrostis tef) accessions from Ethiopia: phylogenetic relationships and mutational hotspots. Peer」. 2020;8:e9314. https://doi.org/10.7717/peerj.9314.

32. Zhang W, Sun YZ, Liu J, Xu C, Zou XH, Chen X, et al. DNA barcoding of Oryza: conventional, specific, and super barcodes. Plant Mol Biol. 2021;105(3):215-28. https://doi.org/10.1007/s11103-020-01054-3.

33. Chen, X.L., Zhou, J.G., Cui, Y.X., Wang, Y., Duan, B.Z., Yao, H. Identification of Ligularia Herbs Using the Complete Chloroplast Genome as a SuperBarcode. Front Pharmacol, 2018; 9: p. 695. https://doi.org/10.3389/fphar. 2018.00695

34. Fu QD, Yu XD, Xia XH, Zheng YQ, Zhang CH. Complete chloroplast genome sequence of Acer nikoense (Sapindaceae). Mitochondrial DNA B. 2020;5(3):3118-9. https://doi.org/10.1080/23802359.2020.1797574.

35. Saina JK, Gichira AW, Li ZZ, Hu GW, Wang QF, Liao K. The complete chloroplast genome sequence of Dodonaea viscosa: comparative and phylogenetic analyses. Genetica. 2018;146(1):101-13. https://doi.org/ 10.1007/s10709-017-0003-X.

36. Zhang ZY, Chen Y, Jiang XB, Zhu P, Li L, Zeng YL, et al. The complete chloroplast genome of Aesculus chinensis. Mitochondrial DNA B. 2019:4(1):1955-6. https://doi.org/10.1080/23802359.2019.1617056.

37. Liu ZG, Zhang JJ, Zhou YX, Liu YF, Hu ZG, Zheng GH, et al. The complete chloroplast genome of Aesculus chinensis var. wilsonii. Mitochondrial DNA B. 2020;5(3):2547-9. https://doi.org/10.1080/23802359.2020.17809 72.

38. Zheng W, Wang W, Harris AJ, Xu XD. The complete chloroplast genome of vulnerable Aesculus wangii (Sapindaceae), a narrowly endemic tree in Yunnan, China. Conserv Genet Resour. 2017;10(3):335-8. https://doi. org/10.1007/s12686-017-0818-x.

39. Zhang DX, Sun K, Xiang QH, Wang XR, Xu JH, Wang Q, et al. The complete chloroplast genome sequence of Aesculus Chinensis Bunge, a major street tree. Mitochondrial DNA B. 2019;4(1):1686-7. https://doi. org/10.1080/23802359.2019.1605857.

40. Wang KY, Li L, Zhao MZ, Li SK, Sun HH, Lv YX, et al. Characterization of the complete chloroplast genome of longan (Dimocarpus longan Lour.) using illumina paired-end sequencing. Mitochondrial DNA B. 2017;2(2):904-6. https://doi.org/10.1080/23802359.2017.1413310.

41. Dong PB, Liu Y, Gao QY, Yang T, Chen XY, Yang JY, et al. Characterization of the complete plastid genome of Acer tsinglingense, an endemic tree species in China. Mitochondrial DNA B. 2019;4(2):4065-6. https://doi. org/10.1080/23802359.2019.1689863.

42. Dai WT, Li SQ, Gao XF, Xu B. The complete chloroplast genome of Acer pentaphyllum (Sapindaceae), a critically endangered maple endemic to China. Mitochondrial DNA B. 2020;5(1):470-1. https://doi.org/10.1080/ 23802359.2019.1704647.

43. Shi ZW, Sun B, Pei NC, Shi X. The complete chloroplast genome of Acer tutcheri Duthie (Acereae, Sapindaceae): an ornamental tree endemic to China. Mitochondrial DNA B. 2020;5(3):2686-7. https://doi.org/10.1080/ 23802359.2020.1787899.

44. Ling LZ, Zhang SD. The complete chloroplast genome of an endangered and endemic species, Acer yangbiense (Aceraceae). Mitochondrial DNA B. 2019;5(1):224-5. https://doi.org/10.1080/23802359.2019.16998 78.

45. Yang HX, Zha X, Cao SL, Wang Y, Gao F, Zhou YJ. Complete chloroplast genome sequence of Acer ginnala, an important ornamental tree. Mitochondrial DNA B. 2020;5(1):609-10. https://doi.org/10.1080/23802 359.2019.1710606.

46. Wang, W.C., Chen, S.Y., Zhang, X.Z. Complete plastomes of 17 species of maples (Sapindaceae: Acer): comparative analyses and phylogenomic implications. Plant Syst. Evol., 2020; 306(3). https://doi.org/10.1007/ s00606-020-01690-8.

47. Chen Z, Qiao OM, Liu BB, Sun HL. Complete chloroplast genome of Eurycorymbus Cavaleriei (Sapindaceae), a tertiary relic rare tree.
Mitochondrial DNA B. 2019;4(2):3250-1. https://doi.org/10.1080/23802 359.2019.1670113.

48. Du XM, Xin GL, Ren XL, Liu HD, Hao N, Jia GL, et al. The complete chloroplast genome of Eurycorymbus cavaleriei (Sapindaceae), a tertiary relic species endemic to China. Conserv Genet Resour. 2018;11(3):283-5. https://doi.org/10.1007/s12686-018-1009-0.

49. Tian XM, Li XL, Miao HY, Xue CL, Wang BL, Guo Y, et al. Complete chloroplast genome of an endangered endemic tree, handeliodendron bodinieri (levl.) rehder (sapindaceae) from karst forests of Southwest China. Mitochondrial DNA B. 2019;4(2):3272-3. https://doi.org/10.1080/ 23802359.2019.1671251.

50. Jin, J.J., Yu, W.B., Yang, J.B., Song, Y., dePamphilis, C.W., Yi, T.S., et al. GetOrganelle: a fast and versatile toolkit for accurate de novo assembly of organelle genomes. Genome Biol., 2020; 21(1): p. 241. https://doi.org/ 10.1186/s13059-020-02154-5.

51. Doyle JJ, Doyle JL. A rapid DNA isolation procedure from small quantities of fresh leaf tissues. Phytochem Bull. 1987;19:11-5.

52. Tong ZG, Wang FR, Zhang Z, Zhao JB, Zhang KC, Yan GH, et al. A method for DNA extraction from mature leaves of fruit trees. J Fruit Sci. 2008;25(1):122-5.

53. Bankevich A, Nurk S, Antipov D, Gurevich AA, Dvorkin M, Kulikov AS, et al. SPAdes: a new genome assembly algorithm and its applications to single-cell sequencing. J Comput Biol. 2012;19(5):455-77. https://doi. org/10.1089/cmb.2012.0021.

54. Langmead B, Salzberg SL. Fast gapped-read alignment with bowtie 2 . Nat Methods. 2012;9(4):357-9. https://doi.org/10.1038/nmeth.1923.

55. Camacho C, Coulouris G, Avagyan V, Ma N, Papadopoulos J, Bealer K, et al. BLAST+: architecture and applications. BMC Bioinformatics. 2009:10(1):421. https://doi.org/10.1186/1471-2105-10-421.

56. Wick RR, Schultz MB, Zobel J, Holt KE. Bandage: interactive visualization of de novo genome assemblies. Bioinformatics. 2015;31(20):3350-2. https://doi.org/10.1093/bioinformatics/btv383.

57. Qu XJ, Moore MJ, Li DZ, Yi TS. PGA: a software package for rapid, accurate, and flexible batch annotation of plastomes. Plant Methods. 2019;15:50. https://doi.org/10.1186/s13007-019-0435-7.

58. Kearse M, Moir R, Wilson A, Stones-Havas S, Cheung M, Sturrock S, et al. Geneious basic: an integrated and extendable desktop software platform for the organization and analysis of sequence data. Bioinformatics. 2012;28(12):1647-9. https://doi.org/10.1093/bioinformatics/bts199.

59. Lohse M, Drechsel O, Bock R. OrganellarGenomeDRAW (OGDRAW): a tool for the easy generation of high-quality custom graphical maps of plastid and mitochondrial genomes. Curr Genet. 2007;52(5-6):267-74. https://doi.org/10.1007/s00294-007-0161-y.

60. Kumar, S., Stecher, G., Tamura, K. MEGA7: Molecular Evolutionary Genetics Analysis version 7.0 for bigger datasets. Mol. Biol. Evol., 2016; 33:1870-1874. https://doi.org/10.1093/molbev/msw054.

61. Kurtz S, Choudhuri JV, Ohlebusch E, Schleiermacher C, Stoye J, Giegerich R. REPuter: the manifold applications of repeat analysis on a genomic scale. Nucleic Acids Res. 2001;29(22):4633-42. https://doi.org/ 10.1093/nar/29.22.4633

62. Beier S, Thiel T, Münch T, Scholz U, Mascher M. MISA-web: a web server for microsatellite prediction. Bioinformatics. 2017;33(16):2583-5. https://doi.org/10.1093/bioinformatics/btx 198.

63. Mayor C, Brudno M, Schwartz JR, Poliakov A, Rubin EM, Frazer KA, et al. VISTA: visualizing global DNA sequence alignments of arbitrary length. Bioinformatics. 2000;16(11):1046-7. https://doi.org/10.1093/bioinforma tics/16.11.1046.

64. Librado P, Rozas J. DnaSP v5: a software for comprehensive analysis of DNA polymorphism data. Bioinformatics. 2009;25(11):1451-2. https:// doi.org/10.1093/bioinformatics/btp187.

65. Darling ACE, Mau B, Blattner FR, Perna NT. Mauve: multiple alignment of conserved genomic sequence with rearrangements. Genome Res. 2004;14(7):1394-403. https://doi.org/10.1101/gr.2289704.

66. Gao FL, Chen CJ, Arab DA, Du ZG, He YH, Ho SYW. EasyCodeML: a visual tool for analysis of selection using CodeML. Ecol Evol. 2019;9(7):3891-8. https://doi.org/10.1002/ece3.5015.

67. Zhang JZ, Nielsen R, Yang ZH. Evaluation of an improved branch-site likelihood method for detecting positive selection at the molecular level. Mol Biol Evol. 2005;22(12):2472-749. https://doi.org/10.1093/ molbev/msi237. 
68. Nguyen LT, Schmidt HA, von Haeseler A, Minh BQ. IQ-TREE: a fast and effective stochastic algorithm for estimating maximum-likelihood phylogenies. Mol Biol Evol. 2015;32(1):268-74. https://doi.org/10.1093/ molbev/msu300.

69. Katoh K, Standley DM. MAFFT multiple sequence alignment software version 7: improvements in performance and usability. Mol Biol Evol. 2013:30(4):772-80. https://doi.org/10.1093/molbev/mst010.

70. Zhang D, Gao FL, Jakovlic I, Zou H, Zhang J, Li WX, et al. PhyloSuite: an integrated and scalable desktop platform for streamlined molecular sequence data management and evolutionary phylogenetics studies. Mol Ecol Resour. 2020;20(1):348-55. https://doi.org/10.1111/1755-0998. 13096.

71. Kalyaanamoorthy S, Minh BQ, Wong TKF, von Haeseler A, Jermiin LS. ModelFinder: fast model selection for accurate phylogenetic estimates. Nat Methods. 2017;14(6):587-9. https://doi.org/10.1038/nmeth.4285.

72. Ronquist, F., Teslenko, M., van der Mark, P., Ayres, D.L., Darling, A., Hohna, S., et al. MrBayes 3.2: Efficient Bayesian Phylogenetic Inference and Model Choice Across a Large Model Space. Syst. Biol., 2012; 61(3): 539-542. https://doi.org/10.1093/sysbio/sys029.

73. Yik, M.H., Kong, B.L., Siu, T.Y., Lau, D.T., Cao, H., Shaw, P.C. Differentiation of Hedyotis diffusa and Common Adulterants Based on Chloroplast Genome Sequencing and DNA Barcoding Markers. Plants, 2021; 10(1). https://doi.org/10.3390/plants10010161.

74. Zhu B, Feng Q, Yu J, Yu Y, Zhu XX, Wang Y, et al. Chloroplast genome features of an important medicinal and edible plant: Houttuynia cordata (Saururaceae). PLoS One. 2020;15(9):e0239823. https://doi.org/10.1371/ journal.pone.0239823.

75. Alzahrani DA, Yaradua SS, Albokhari EJ, Abba A. Complete chloroplast genome sequence of Barleria prionitis, comparative chloroplast genomics and phylogenetic relationships among Acanthoideae. BMC Genomics. 2020;21(1):393. https://doi.org/10.1186/s12864-020-06798-2.

76. Dong, F., Lin, Z.C., Lin, J., Ming, R., Zhang, W.P. Chloroplast Genome of Rambutan and Comparative Analyses in Sapindaceae. Plants, 2021; 10(2). https://doi.org/10.3390/plants10020283.

77. Wang, R.K., Fan, J.S., Chang, P., Zhu, L., Zhao, M.R., Li, L.L. Genome Survey Sequencing of Acer truncatum Bunge to Identify Genomic Information, Simple Sequence Repeat (SSR) Markers and Complete Chloroplast Genome. Forests, 2019; 10(2). https://doi.org/10.3390/f10020087.

78. Yu, T., Gao, J., Huang, B.H., Dayananda, B., Ma, W.B., Zhang, Y.Y., et al. Comparative Plastome Analyses and Phylogenetic Applications of the Acer Section Platanoidea. Forests, 2020; 11(4). https://doi.org/10.3390/ f11040462.

79. Kim SC, Baek SH, Hong KN, Lee JW. Characterization of the complete chloroplast genome of Koelreuteria paniculata (Sapindaceae). Conserv Genet Resour. 2017;10(1):69-72. https://doi.org/10.1007/ s12686-017-0767-4.

80. Ma QY, Wang YA, Zhu L, Bi CW, Li SX, Li SS, et al. Characterization of the complete chloroplast genome of Acer truncatum Bunge (Sapindales: Aceraceae): a new Woody oil tree species producing Nervonic acid. Biomed Res Int. 2019;2019:7417239. https://doi.org/10.1155/2019/ 7417239 .

81. Lin N, Moore MJ, Deng T, Sun H, Yang LS, Sun YX, et al. Complete plastome sequencing from Toona (Meliaceae) and phylogenomic analyses within Sapindales. Appl Plant Sci. 2018;6(4):e1040. https://doi.org/10. 1002/aps3.1040.

82. Kim HT, Pak JH, Kim JS. The complete chloroplast genome sequence of Acer takesimense (Sapindaceae), an endemic to Ullenung Island of Korea. Mitochondrial DNA B. 2019;4(1):1531-2. https://doi.org/10.1080/ 23802359.2019 .1601521$.

83. Rono PC, Dong X, Yang JX, Mutie FM, Oulo MA, Malombe I, et al. Initial complete chloroplast genomes of Alchemilla (Rosaceae): comparative analysis and phylogenetic relationships. Front Genet. 2020;11:560368. https://doi.org/10.3389/fgene.2020.560368.

84. Chi, X.F., Zhang, F.Q., Dong, Q., Chen, S.L. Insights into Comparative Genomics, Codon Usage Bias, and Phylogenetic Relationship of Species from Biebersteiniaceae and Nitrariaceae Based on Complete Chloroplast Genomes. Plants, 2020; 9(11). https://doi.org/10.3390/plants9111 605.

85. Wang L, He N, Li Y, Fang YM, Zhang FL. Complete chloroplast genome sequence of Chinese lacquer tree (Toxicodendron vernicifluum,
Anacardiaceae) and its phylogenetic significance. Biomed Res Int. 2020;2020:9014873. https://doi.org/10.1155/2020/9014873.

86. Luo XY, Yu YB, Peng HY, Tang GD. The complete chloroplast genome sequence of the drought-tolerant maple Acer coriaceifolium H. Lév. (Aceraceae). Mitochondrial DNA B. 2019;4(1):1131-2. https://doi.org/10. 1080/23802359.2019.1586469.

87. Wu, L.W., Nie, L.P., Xu, Z.C., Li, P., Wang, Y., He, C.N., et al. Comparative and Phylogenetic Analysis of the Complete Chloroplast Genomes of Three Paeonia Section Moutan Species (Paeoniaceae). Front. Genet., 2020;11:980. https://doi.org/10.3389/fgene.2020.00980.

88. Cheon KS, Kim KA, Kwak M, Lee B, Yoo KO. The complete chloroplast genome sequences of four Viola species (Violaceae) and comparative analyses with its congeneric species. PLoS One. 2019;14(3):e0214162. https://doi.org/10.1371/journal.pone.0214162.

89. Li, D.M., Zhao, C.Y., Liu, X.F. Complete Chloroplast Genome Sequences of Kaempferia Galanga and Kaempferia Elegans: Molecular Structures and Comparative Analysis. Molecules, 2019; 24(3). https://doi.org/10.3390/ molecules24030474.

90. Singh RB, Mahenderakar MD, Jugran AK, Singh RK, Srivastava RK. Assessing genetic diversity and population structure of sugarcane cultivars, progenitor species and genera using microsatellite (SSR) markers. Gene. 2020;753:144800. https://doi.org/10.1016/j.gene.2020.144800.

91. Ramzan M, Sarwar S, Kauser N, Saba R, Hussain I, Shah AA, et al. Assessment of inter simple sequence repeat (ISSR) and simple sequence repeat (SSR) markers to reveal genetic diversity among Tamarix ecotypes. J King Saud Univ Sci. 2020;32(8):3437-46. https://doi.org/10. 1016/j.jksus.2020.10.003.

92. Motahari, B., Shabanian, N., Rahmani, M.S., Mohammad-Hasani, F Genetic diversity and genetic structure of Acer monspessulanum L across Zagros forests of Iran using molecular markers. Gene, 2021; 769: p. 145245. https://doi.org/10.1016/j.gene.2020.145245.

93. Zhao ZY, Wang X, Yu Y, Yuan S, Jiang D, Zhang YJ, et al. Complete chloroplast genome sequences of Dioscorea: characterization, genomic resources, and phylogenetic analyses. PeerJ. 2018;6:e6032. https://doi. org/10.7717/peerj.6032.

94. Li W, Zhang C, Guo X, Liu Q, Wang K. Complete chloroplast genome of Camellia japonica genome structures, comparative and phylogenetic analysis. PLoS One. 2019;14(5):e0216645. https://doi.org/10.1371/journ al.pone.0216645.

95. Zhang, F.J., Wang, T., Shu, X.C., Wang, N., Zhuang, W.B., Wang, Z. Complete Chloroplast Genomes and Comparative Analyses of L. Chinensis, L. anhuiensis, and L. aurea (Amaryllidaceae). Int. J. Mol. Sci., 2020; 21(16). https://doi.org/10.3390/ijms21165729.

96. Wen F, Wu XZ, Li TJ, Jia ML, Liu XS, Liao L. The complete chloroplast genome of Stauntonia chinensis and compared analysis revealed adaptive evolution of subfamily Lardizabaloideae species in China. BMC Genomics. 2021;22(1):161. https://doi.org/10.1186/s12864-021-07484-7.

97. Khayi, S., Gaboun, F., Pirro, S., Tatusova, T., El Mousadik, A., Ghazal, H., et al. Complete Chloroplast Genome of Argania spinosa: Structural Organization and Phylogenetic Relationships in Sapotaceae. Plants, 2020;9(10):1354. https://doi.org/10.3390/plants9101354.

98. Meng D, Xiaomei Z, Wenzhen K, Xu Z. Detecting useful genetic markers and reconstructing the phylogeny of an important medicinal resource plant, Artemisia selengensis, based on chloroplast genomics. PLoS One. 2019;14(2):e0211340. https://doi.org/10.1371/journal.pone.0211340.

99. Khan, A., Asaf, S., Khan, A.L., Al-Harrasi, A., Al-Sudairy, O., AbdulKareem, N.M., et al. First complete chloroplast genomics and comparative phylogenetic analysis of Commiphora gileadensis and C. foliacea: Myrrh producing trees. PLoS One, 2019; 14(1): e0208511. https://doi.org/10. 1371/journal.pone.0208511.

100. Hong, Z., Wu, Z.Q., Zhao, K.K., Yang, Z.J., Zhang, N.N., Guo, J.Y., et al. Comparative Analyses of Five Complete Chloroplast Genomes from the Genus Pterocarpus (Fabacaeae). Int. J Mol Sci, 2020; 21(11). https://doi. org/10.3390/ijms21113758.

101. Ding, S.X., Dong, X., Yang, J.X., Guo, C., Cao, B.B., Guo, Y., et al. Complete Chloroplast Genome of Clethra fargesii Franch., an Original Sympetalous Plant from Central China: Comparative Analysis, Adaptive Evolution, and Phylogenetic Relationships. Forests, 2021; 12(4). https://doi.org/10. 3390/f12040441.

102. Li, X.Q., Zuo, Y.J., Zhu, X.X., Liao, S., Ma, J.S. Complete Chloroplast Genomes and Comparative Analysis of Sequences Evolution among 
Seven Aristolochia (Aristolochiaceae) Medicinal Species. Int. J. Mol. Sci., 2019; 20(5). https://doi.org/10.3390/ijms20051045.

103. Shi C, Han K, Li L, Seim I, Lee SM, Xu X, et al. Complete chloroplast genomes of 14 mangroves: phylogenetic and comparative genomic Analyses. Biomed Res Int. 2020;2020:8731857. https://doi.org/10.1155/ 2020/8731857.

\section{Publisher's Note}

Springer Nature remains neutral with regard to jurisdictional claims in published maps and institutional affiliations.

- fast, convenient online submission

- thorough peer review by experienced researchers in your field

- rapid publication on acceptance

- support for research data, including large and complex data types

- gold Open Access which fosters wider collaboration and increased citations

- maximum visibility for your research: over $100 \mathrm{M}$ website views per year

At BMC, research is always in progress.

Learn more biomedcentral.com/submissions 